\title{
Activity-dependent Increases in Local Oxygen Consumption Correlate with Postsynaptic Currents in the Mouse Cerebellum In Vivo
}

\author{
Claus Mathiesen, ${ }^{1}$ Kirsten Caesar, ${ }^{1}$ Kirsten Thomsen, ${ }^{1}$ Tycho M. Hoogland, ${ }^{2}$ Brent M. Witgen, ${ }^{1}$ Alexey Brazhe, ${ }^{3}$ \\ and Martin Lauritzen ${ }^{1,4}$ \\ ${ }^{1}$ Department of Neuroscience and Pharmacology, and Center for Healthy Aging, University of Copenhagen, DK-2200 Copenhagen N, Denmark, \\ ${ }^{2}$ Netherlands Institute for Neuroscience, NL-1000 GC Amsterdam, The Netherlands, ${ }^{3}$ Biological Faculty, Moscow State University, Moscow 119991, Russia, \\ and ${ }^{4}$ Department of Clinical Neurophysiology, Glostrup Hospital, DK-2600 Glostrup, Denmark
}

Evoked neural activity correlates strongly with rises in cerebral metabolic rate of oxygen $\left(\mathrm{CMRO}_{2}\right)$ and cerebral blood flow $(\mathrm{CBF})$. Activity-dependent rises in $\mathrm{CMRO}_{2}$ fluctuate with ATP turnover due to ion pumping. In vitro studies suggest that increases in cytosolic $\mathrm{Ca}^{2+}$ stimulate oxidative metabolism via mitochondrial signaling, but whether this also occurs in the intact brain is unknown. Here we applied a pharmacological approach to dissect the effects of ionic currents and cytosolic $\mathrm{Ca}^{2+}$ rises of neuronal origin on activitydependent rises in $\mathrm{CMRO}_{2}$. We used two-photon microscopy and current source density analysis to study real-time $\mathrm{Ca}^{2+}$ dynamics and transmembrane ionic currents in relation to $\mathrm{CMRO}_{2}$ in the mouse cerebellar cortex in vivo. We report a direct correlation between $\mathrm{CMRO}_{2}$ and summed (i.e., the sum of excitatory, negative currents during the whole stimulation period) field EPSCs ( $\sum$ fEPSCs) in Purkinje cells (PCs) in response to stimulation of the climbing fiber (CF) pathway. Blocking stimulus-evoked rises in cytosolic $\mathrm{Ca}^{2+}$ in $\mathrm{PCs}$ with the $\mathrm{P} / \mathrm{Q}$-type channel blocker $\omega$-agatoxin-IVA $\left(\omega\right.$-AGA), or the $\mathrm{GABA}_{\mathrm{A}}$ receptor agonist muscimol, did not lead to a time-locked reduction in $\mathrm{CMRO}_{2}$, and excitatory synaptic or action potential currents. During stimulation, neither $\omega$-AGA or ( $\mu$-oxo)-bis-(transformatotetramine-ruthenium) (Ru360), a mitochondrial $\mathrm{Ca}^{2+}$ uniporter inhibitor, affected the ratio of $\mathrm{CMRO}_{2}$ to fEPSCs or evoked local field potentials. However, baseline $\mathrm{CBF}$ and $\mathrm{CMRO}_{2}$ decreased gradually with Ru360. Our data suggest that in vivo activity-dependent rises in $\mathrm{CMRO}_{2}$ are correlated with synaptic currents and postsynaptic spiking in PCs. Our study did not reveal a unique role of neuronal cytosolic $\mathrm{Ca}^{2+}$ signals in controlling $\mathrm{CMRO}_{2}$ increases during $\mathrm{CF}$ stimulation.

\section{Introduction}

Coupling of neuronal activity, energy metabolism, and blood flow forms the basis of noninvasive functional imaging used to map brain function in humans (Raichle and Mintun, 2006). Glucose oxidation provides nearly all the energy required by neurons to support brain activity in the resting state (Clarke and Sokoloff, 1994) as well as during activation (Lin et al., 2010). It is now recognized that neurotransmitter signaling plays a key role in regulating cerebral blood flow (CBF), and both neurons and astrocytes mediate this control (Lauritzen, 2005; Attwell et al., 2010). In comparison, less is known regarding the local in vivo control of the cerebral metabolic rate of $\mathrm{O}_{2}\left(\mathrm{CMRO}_{2}\right)$, as most knowledge of mitochondrial function was obtained from isolated

Received Sept. 5, 2011; revised 0ct. 20, 2011; accepted 0ct. 20, 2011.

Author contributions: C.M., K.C., K.T., A.B., and M.L. designed research; C.M., K.C., K.T., T.M.H., B.M.W., and A.B. performed research; C.M., K.T., T.M.H., and A.B. analyzed data; C.M., K.T., T.M.H., A.B., and M.L. wrote the paper.

This study was supported by the Lundbeck Foundation via the Lundbeck Foundation Center for Neurovascular Signaling, the NOVO-Nordisk Foundation, the Danish Medical Research Council, the NORDEA foundation for Center for Healthy Aging, and Foundation Leducq. We thank Micael Lønstrup for excellent surgical assistance and Peter Rasmussen for providing the initial CSD MatLab script.

Correspondence should be addressed to Dr. Claus Mathiesen, Institute of Neuroscience and Pharmacology, Panum Institute 18.5, Blegdamsvej 3, DK-2200 Copenhagen N, Denmark. E-mail: mathiesenator@gmail.com.

DOI:10.1523/JNEUROSCI.4526-11.2011

Copyright $\odot 2011$ the authors $\quad 0270-6474 / 11 / 3118327-11 \$ 15.00 / 0$ mitochondria, dissociated cell cultures, or brain slices (Kann and Kovács, 2007). $\mathrm{CMRO}_{2}$ is controlled by the ADP/ATP ratio, as well as by changes in the mitochondrial $\mathrm{Ca}^{2+}$ concentration that stimulate the activity of tricarboxylic acid (TCA) cycle dehydrogenases and central enzymes in the respiratory chain (Gunter et al., 2004). In addition, respiration is controlled by the $\mathrm{Ca}^{2+}$ dependent mitochondrial aspartate-glutamate transporter, which increases mitochondrial nicotinamide adenine dinucleotide (NADH) levels (Satrústegui et al., 2007). Indeed, recent studies suggest that glutamate-dependent oxidative phosphorylation in mitochondria is exclusively triggered by extramitochondrial $\mathrm{Ca}^{2+}$ in physiological concentration ranges (Gellerich et al., 2010). Furthermore, rapid rises in oxygen consumption mediated by increased cytosolic $\mathrm{Ca}^{2+}$ concentrations have been demonstrated in cultured Purkinje cells (PCs) (Hayakawa et al., 2005). These observations support the notion that cytosolic $\mathrm{Ca}^{2+}$ signaling may function as a rapid feedforward mechanism to control $\mathrm{CMRO}_{2}$ and thereby control cytosolic ATP levels in nervous system tissue (Gunter et al., 2004); however, the influence of cytosolic $\mathrm{Ca}^{2+}$ on $\mathrm{CMRO}_{2}$ has not been investigated in the intact brain. We studied this relationship in vivo with preserved perfusion (i.e., glucose and oxygen supplies), testing the hypothesis that activity-driven increases in cytosolic $\mathrm{Ca}^{2+}$ in PCs are rate 
A

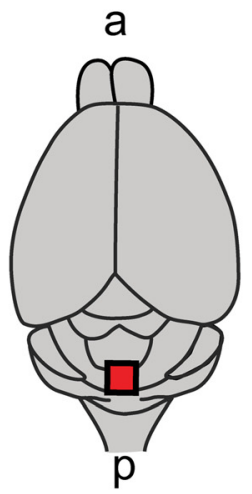

$\mathrm{D}$

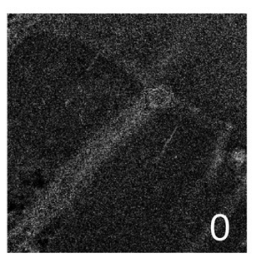

B
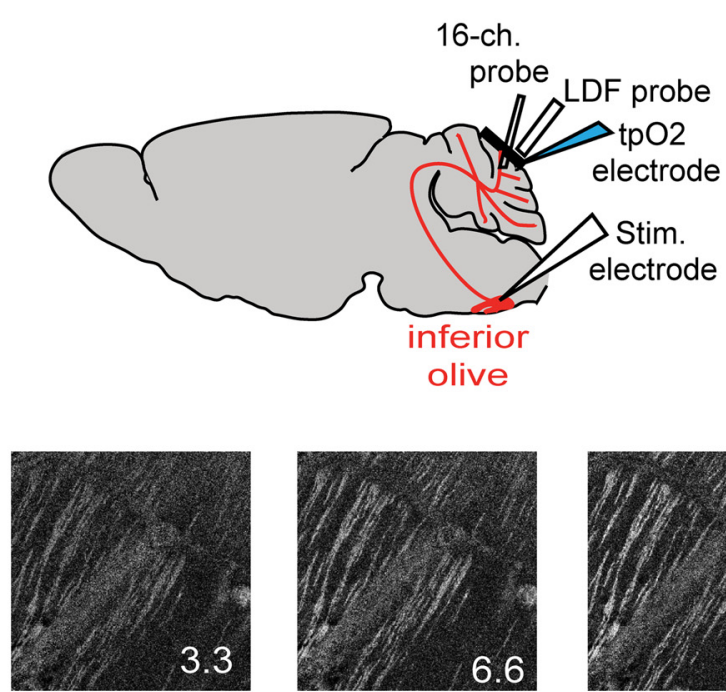

C

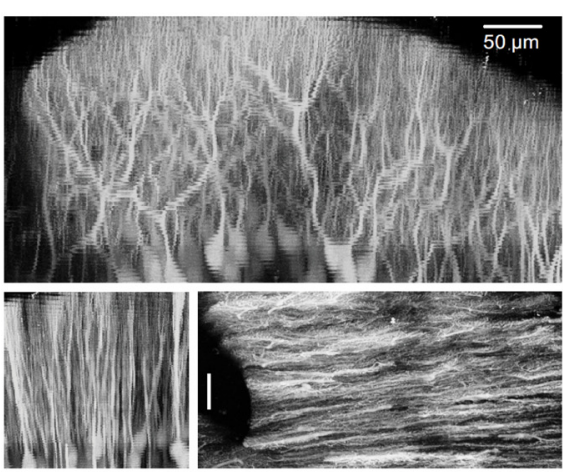

Stimulation of climbing fibers at $10 \mathrm{~Hz}$ for $15 \mathrm{~s}$

Figure 1. Experimental setup and functional anatomy of mouse cerebellar PCs. A, Dorsal view of the mouse brain, indicating the location of the cranial window over the cerebellar vermis lobule VI (red box). a, Anterior, p, posterior. B, Side view of the mouse brain, indicating placement of 16-channel (16-ch.) probe, LDF probe, tp $\mathrm{O}_{2}$ electrode and bipolar stimulation (stim.) electrode. $\boldsymbol{C}$, Counterclockwise order: sagittal, transverse, and top views of PCs in the cerebellum of $P(p 2-E G F P$ mice expressing cell-specific green fluorescent. $D$, Top, The sagittal orientation of $P C($ dendrites. Time series of $\mathrm{CF}$-evoked $\mathrm{Ca}^{2+}$ responses (top view, with numbers indicating time in seconds from stimulation onset and yellow bar indicating the $10 \mathrm{~Hz}, 15 \mathrm{~s} \mathrm{stimulus)}$.

limiting for the corresponding $\mathrm{CMRO}_{2}$ responses. Our data suggest that cytosolic $\mathrm{Ca}^{2+}$ per se does not directly modulate $\mathrm{CMRO}_{2}$ responses; instead, our results suggest that in vivo $\mathrm{CMRO}_{2}$ responses correlate significantly with postsynaptic currents.

\section{Materials and Methods}

\section{Animal handling}

All procedures involving animals were approved by the Danish National Ethics Committee according to the guidelines set forth in the European Council Convention for the Protection of Vertebrate Animals used for Experimental and Other Scientific Purposes. Forty four male white Naval Medical Research Institute mice [6-8 weeks old, Crl:NMRI(Han)] were examined using pharmacological interventions designed to inhibit $\mathrm{Ca}^{2+}$ entry into either cells or mitochondria in the vermis region, lobule VI of the cerebellar cortex. CBF, tissue partial pressure of oxygen $\left(\mathrm{tpO}_{2}\right)$ and excitatory synaptic currents as indicated by either current source density (CSD) analysis or extracellular local field potentials (LFPs) in response to climbing fiber (CF) stimulation were measured in 32 mice, while cytosolic $\mathrm{Ca}^{2+}$ responses to the same stimulation paradigm were examined in 12 mice using two-photon microscopy. To compare stimulus-evoked $\mathrm{Ca}^{2+}$ responses to the anatomy of cerebellar PCs shown in Figure $1 C$, we also examined three transgenic Pcp2 mice (9-11 weeks old) expressing the green fluorescent Purkinje cell protein2 (Pcp2-EGFP; Jackson Laboratory).

Mice were anesthetized by intraperitoneal injections of a mixture of ketamine $(60 \mathrm{mg} / \mathrm{kg}$ ) and xylazine (10 mg/kg) (Sigma-Aldrich), and were given supplemental doses of ketamine every $20 \mathrm{~min}$. Body temperature was maintained at $37^{\circ} \mathrm{C}$ using a temperature controller and heating blanket (model TC-1000 Temperature Controller, CWE). The trachea was cannulated for mechanical ventilation with a small-animal ventilator (SAAR-830, CWE). A catheter (TYGON S54HL $0.010 \times 0.030 \mathrm{~mm}$, VWR International) was inserted into the left femoral artery for continuous monitoring of blood pressure. A blood sample taken at the beginning of each experiment was used to adjust respiration to obtain physiological blood gas values $\left[\mathrm{pO}_{2}, 95-110 \mathrm{mmHg}\right.$; partial pressure of $\mathrm{CO}_{2}, 35-40 \mathrm{mmHg}$; $\left.\mathrm{pH}, 7.35-7.45\right]$. A custom-made metal plate allowing cranial access was fixed to the skull with cyanoacrylate gel (Loctite
Adhesives). A craniotomy ( $\sim 4 \mathrm{~mm}$ diameter) was made above lobule VI of the medial vermis region of the cerebellum, and the dura was removed. The craniotomy was filled with $1 \%$ agarose (type III-A, low electroendosmosis; Sigma-Aldrich) and was moistened with artificial CSF (aCSF) (in mM as follows: $\mathrm{NaCl} 120, \mathrm{KCl} 2.8, \mathrm{NaHCO}_{3} 22, \mathrm{CaCl}_{2} 1.45$, $\mathrm{Na}_{2} \mathrm{HPO}_{4} 1, \mathrm{MgCl}_{2} 0.876$, and glucose $\left.2.55 ; \mathrm{pH} 7.4\right)$ at $37^{\circ} \mathrm{C}$, aerated with $95 \%$ air $/ 5 \% \mathrm{CO}_{2}$. For imaging experiments using the twophoton microscope, part of the craniotomy was covered with a glass coverslip, which permitted pharmacological interventions and electrical recordings. At the end of experiments, mice were killed by intravenous injection of air followed by decapitation.

\section{Climbing fiber stimulation}

A coated, bipolar stainless-steel electrode $(0.25 \mathrm{~mm}$ contact separation; SNEX 200, RMI Corporation) was stereotactically lowered into the inferior olive as described previously (Caesar et al., 2003). PCs were identified by their ability to fire simple spikes (SSs) and complex spikes (CSs) spontaneously, with the production of a complex spike 5-8 ms after electrical stimulation of the inferior olive. Stimulation of CFs also resulted in an LFP with a classical laminar profile and potential reversal (Mathiesen et al., 1998). Positioning was optimized by means of the maximal response of LFP in the cerebellar vermis region to continuous low-frequency stimulation $(0.5 \mathrm{~Hz})$. Pulses of $0.2 \mathrm{~ms}$ constant current with an intensity of $0.15 \mathrm{~mA}$ (ISO-flex, A.M.P.I.) were used at 2, 5, and 10 $\mathrm{Hz}$ for $15 \mathrm{~s}$. The test stimulation during pharmacological interventions was $10 \mathrm{~Hz}$ for $15 \mathrm{~s}$. The stimulation was controlled by a Sequencer file running within the Spike2 software (version 7.02, Cambridge Electronic Design).

\section{Electrophysiological recordings}

PC spike activity and LFPs were recorded with single-barreled glass microelectrodes (borosilicate glass; tip diameter 2-3 $\mu \mathrm{m}$, outer diameter $1.5 \mathrm{~mm}$; inner diameter $0.86 \mathrm{~mm}$; Sutter Instrument) containing aCSF at a depth of 50-100 $\mu \mathrm{m}$ below the brain surface. An $\mathrm{Ag} / \mathrm{AgCl}$ ground electrode was placed near the cranial window submerged in aCSF. These analog signals were first amplified using a differential amplifier (gain $\times 10$, bandwidth $0.1-10,000 \mathrm{~Hz}$; model DP-311, Warner Instruments) followed by additional amplification using CyberAmp 380 (Molecular Devices; gain $\times 100$, bandwidth 0.1-10,000 Hz). 
In electrophysiological experiments, laminar LFP profiles from which CSD maps were calculated (see CSD calculation, below) were recorded using a vertical 16-channel Michigan probe with $50 \mu \mathrm{m}$ between electrodes (A1x16-5 mm-50-413, NeuroNexus Technologies) and a 16-channel amplifier (gain $\times 1000$, bandwidth $1-10,000 \mathrm{~Hz}$; PGA16, Multichannel Systems). All electrical analog signals were digitally sampled at least five times the low-pass filter frequency using a power $1401 \mathrm{mk}$ II interface (Cambridge Electronic Design) connected to a personal computer running Spike2 software.

Stimulation artifacts were removed from PC spike traces with a Spike2 script (artrem.s2s, Cambridge Electronic Design). PC spike activity was quantified by calculating the root mean square (rms) of the spike trace, while spike interval histogram (INTH) analysis was applied to illustrate changes in PC spiking rhythm. The poststimulus refractory period is the period from the end of stimulation to the recovery of spiking to prestimulus levels and reflects the activity of the $\mathrm{Ca}^{2+}$-gated $\mathrm{K}^{+}$current $\left(g \mathrm{~K}_{\mathrm{Ca}}\right)$ (Llinas, 1981; Womack et al., 2009).

\section{CSD calculation}

CSD is related to the second-order spatial derivative of the LFP under the assumptions of constant extracellular electrical conductivity, homogeneous cortical in-plane activity and equal distance between recorded potentials (Nicholson and Freeman, 1975; Nakagawa and Matsumoto, 1998). CSD was calculated from averaged laminar LFP profiles using custom-written Matlab scripts (The MathWorks), which calculated the difference of the difference between LFP amplitudes for every running set of three neighboring channels. The CSD maps obtained in this manner identified the location and amplitude of the negative and positive currents. At a cortical depth of $50 \mu \mathrm{m}$, the amplitude of the negative current is proportional to the magnitude of the field (i.e., extracellular) EPSC (fEPSC) and reflects $\mathrm{Na}^{+}$influx into PCs via AMPA receptor channels, while the delayed positive current represents $\mathrm{K}^{+}$efflux out of PCs via P/Q-type $g K_{\mathrm{Ca}}$ (Llinas, 1981; Womack et al., 2009). The reverse current pattern is observed at a depth of $100 \mu \mathrm{m}$ due to the anatomical and electrophysiological properties of the PCs (Llinas, 1981). We calculated the summed fEPSCs ( $\sum$ fESPC) as fESPC amplitude $\times$ stimulation frequency $\times$ duration of stimulation train, which represents the transmembrane $\mathrm{Na}^{+}$flux into PCs during the stimulation period (Mathiesen et al., 1998).

\section{Cerebellar cortical blood flow measurement}

CBF was recorded continuously using a laser-Doppler flowmetry (LDF) probe at a fixed position $0.3 \mathrm{~mm}$ above the pial surface in a region devoid of large vessels (wavelength $780 \mathrm{~nm} ; 250 \mu \mathrm{m}$ fiber separation allowing CBF measurement to a depth of $1 \mathrm{~mm}$; Perimed) (Fabricius et al., 1997). The probe was placed close to the microelectrodes recording electrophysiological variables and oxygen (Fig. $1 B$ ). The LDF signal was smoothed with a time constant of $0.2 \mathrm{~s}$ (PeriFlux 4001 Master, Perimed), sampled at $10 \mathrm{~Hz}$, analog-to-digital (A/D) converted, and digitally recorded and smoothed (time constant $1 \mathrm{~s}$ ) using the Spike2 software. The LDF method does not measure CBF in absolute terms, but is valid in determining relative changes in CBF during moderate flow increases (Fabricius and Lauritzen, 1996). Evoked rises of CBF are expressed as a percentage of baseline. No significant changes in CBF baseline were observed during the experiments.

\section{Local tp $\mathrm{O}_{2}$ measurements}

Local $\mathrm{tpO}_{2}$ was recorded with a modified Clark-type polarographic oxygen microelectrode (OX-10, Unisense A/S). The small tip size (3-5 $\mu \mathrm{m})$ assured reliable $\mathrm{tpO}_{2}$ measurements, and its built-in guard cathode removed all oxygen from the electrolyte reservoir, enabling the measurement of $\mathrm{tpO}_{2}$ over time under different treatment conditions with excellent long-term stability (signal drift $0-0.5 \% / \mathrm{h}$ ). The field of sensitivity is a sphere of $2 \times$ tip diameter. The oxygen electrodes were calibrated in air-saturated and oxygen-free saline $\left(0.9 \%\right.$ at $\left.37^{\circ} \mathrm{C}\right)$ before and after each experiment, with reproducible oxygen measurements. The tip of the $\mathrm{O}_{2}$ microelectrode was positioned in the center of the sampling volume of the laser-Doppler probe (Fabricius et al., 1997) at a depth of 50-75 $\mu \mathrm{m}$, where maximal fEPSCs were found. The oxygen electrode was connected to a high-impedance picoampere meter (PA 2000,
Table 1. Control levels of dendritic $\mathrm{Ca}^{2+}$ coverage, spike activity, $\mathrm{CSD}, \mathrm{CBF}, \mathrm{tpO}{ }_{2}$, and $\mathrm{CMRO}_{2}$ responses to $\mathrm{CF}$ stimulation (15 s at $10 \mathrm{~Hz}$ )

\begin{tabular}{|c|c|}
\hline & Control levels \\
\hline \multicolumn{2}{|l|}{$\mathrm{Ca}^{2+}(N=12)$} \\
\hline Peak (\%) & $13.6 \pm 2.3$ \\
\hline Coverage (\%) & $20.5 \pm 3.9$ \\
\hline \multicolumn{2}{|l|}{ Spikes $(N=7)$} \\
\hline Spontaneous (rms) & $0.43 \pm 0.09$ \\
\hline Evoked (rms) & $0.33 \pm 0.09$ \\
\hline Postrefractory (s) & $16.0 \pm 4.9$ \\
\hline \multicolumn{2}{|l|}{$\operatorname{CSD}(N=9)$} \\
\hline Negative current $\left(\mathrm{mV}^{2}\right)$ & $-0.51 \pm 0.06$ \\
\hline Positive current $\left(\mathrm{mV}^{2}\right)$ & $0.206 \pm 0.076$ \\
\hline \multicolumn{2}{|l|}{$\mathrm{CBF}(N=16)$} \\
\hline Amplitude ( $\%$ of baseline) & $28.6 \pm 2.9$ \\
\hline \multicolumn{2}{|l|}{$\operatorname{tp} 0_{2}(N=16)$} \\
\hline Amplitude (mmHg) & $-4.9 \pm 0.9$ \\
\hline Baseline (mmHg) & $28.4 \pm 1.7$ \\
\hline \multicolumn{2}{|l|}{$\mathrm{CMRO}_{2}(\mathrm{~N}=16)$} \\
\hline Amplitude (\% of baseline) & $19.9 \pm 2.1$ \\
\hline
\end{tabular}

Unisense A/S) sensing the currents of the oxygen electrode. Signals were $\mathrm{A} / \mathrm{D}$ converted and recorded at $10 \mathrm{~Hz}$ (Power 1401 data acquisition interface and Spike 2 software). Noise, including heartbeat and mechanical ventilation artifacts, were minimized using smoothing (time constant $1 \mathrm{~s}$; Spike 2). Current recordings were transformed to millimeters of mercury using the calibrations with saturated and oxygen-free standard solutions.

\section{Calculation of $\mathrm{CMRO}_{2}$}

$\mathrm{CMRO}_{2}$ was calculated off-line from simultaneously obtained recordings of $\mathrm{tpO}_{2}$ and $\mathrm{CBF}$. Baseline values of $\mathrm{tpO}_{2}$ and $\mathrm{CBF}$ were taken as the mean of a $20 \mathrm{~s}$ period obtained before the onset of stimulation. These values were then combined with reported values for $\mathrm{CBF}$ and $\mathrm{CMRO}_{2}$ previously obtained (Zhu et al., 2002) in rats $\left(53 \mathrm{ml}(100 \mathrm{~g})^{-1} \mathrm{~min}^{-1}\right.$ and $219 \mu \mathrm{mol}(100 \mathrm{~g})^{-1} \mathrm{~min}^{-1}$, respectively) to calculate the corresponding effective diffusion coefficient of oxygen in brain tissue $(L)$. The pertinent relationship is as follows:

$$
\mathrm{tpO}_{2}=P_{50} h \sqrt{\frac{2 C_{a} \mathrm{CBF}}{\mathrm{CMRO}_{2}}-1}-\frac{2 \mathrm{CMRO}_{2}}{3 L},
$$

where $P_{50}$ is the half-saturation tension of the oxygen-hemoglobin dissociation curve, $h$ is the Hill coefficient of the same dissociation curve, and $C_{a}$ is the arterial oxygen concentration (Gjedde et al., 2005). Standard values used for these calculations were as follows: $P_{50}=36.0$ $\mathrm{mmHg} ; h=2.7$; and $C_{a}=8 \mu \mathrm{mol} \mathrm{ml}^{-1}$; these values correspond to an $L$ value of $11.3 \mu \mathrm{mol}(100 \mathrm{~g})^{-1} \mathrm{~min}^{-1} \mathrm{mmHg}^{-1}$.

\section{Two-photon imaging}

Twelve mice were examined with a commercial two-photon microscope (SP5 multiphoton/confocal Laser Scanning Microscope, Leica), a MaiTai HP Ti:Sapphire laser (Millennia Pro, Spectra Physics), and a $20 \times 1.0$ numerical aperture water-immersion objective (Leica). The excitation wavelength was set to $820 \mathrm{~nm}$. The frame size was typically $128 \times 128$ pixels ( $185 \mathrm{~ms} /$ frame), or $256 \times 256$ pixels ( $344 \mathrm{~ms} /$ frame), while a size of $512 \times 512$ pixels $(661 \mathrm{~ms} /$ frame $)$ was used to obtain an overview of dendrite activation.

\section{Bolus loading of synthetic $\mathrm{Ca}^{2+}$ indicator}

Oregon Green BAPTA-1/AM (10 mM OGB-1/AM, Invitrogen) in dimethylsulfoxide plus 20\% Pluronic F-127 (BASF Global) was diluted in aCSF to yield a final dye concentration of $0.8 \mathrm{~mm}$. The dye was then bolus loaded through a micropipette at two to four sites at depths of 50-100 $\mu \mathrm{m}$ below the surface of the cerebellar cortex (4-6 psi, 1-5 s; Pneumatic Pump, World Precision Instruments). 


\section{Image analysis}

Stimulation of the inferior olive resulted in robust activation of CFs, which evoked $\mathrm{Ca}^{2+}$ increases in PC dendrites in the field of view. Two methods were applied to extract the $\mathrm{Ca}^{2+}$ elevations: spatial independent component analysis (ICA) and a correlationbased method.

Spatial independent component analysis. Spatial ICA using the fast ICA algorithm developed by Aapo Hyvärinen (www.cis-.hut.fi/projects/ ica/fastica/) was applied to $128 \times 128$-pixel frames. Evoked responses were attributable to a single spatial component, with activated dendrites appearing as tubular structures with high pixel intensity and matching the sagittal orientation of PC dendrites in Pcp2-EGFP mice (Fig. 1D). To assess drug effects on evoked calcium responses, we used the parameter coverage, which represents the fraction of pixels within a component that had intensity values above a set threshold in response to stimulation relative to the total number of pixels. This intensity threshold was set as the whole-frame mean intensity plus $5 \mathrm{SDs}$. Coverage was a more reliable measure of direct drug effects than fluorescence intensity changes, since the remaining responding areas after drug applications often showed similar intensity changes to control conditions, while coverage changed significantly.

Correlation-based method. A correlationbased method was applied to $256 \times 256$-pixel frames. For each pixel, time tracks after mean centering and normalization to the SDs were cross-correlated with an "on-off" signal of the following form:

$$
\begin{aligned}
& 0.5\left(1+\left(10\left(t-\mathrm{t}_{\text {start }}\right)\right)\right. \\
& \left.\cdot \tanh \left(-10\left(t-t_{\text {stop }}\right)\right)\right)
\end{aligned}
$$

where $t_{\text {start }}$ and $t_{\text {stop }}$ define the stimulation period. This transformation results in a matrix of correlation coefficients measuring the similarity of the time course to a step-like signal that increases over the period of stimulation. These maps were binarized by $95 \%$ significance levels, and only pixels with at least five neighbors within a radius of three pixels were preserved. Ninety-five percent significance levels were derived from Monte Carlo simulations in which the same procedure was applied to $10^{6}$ surrogate random time courses with values sampled from the Poisson distribution for each stimulation period. The time courses, spatially averaged from activated areas, were fitted with smoothing cubic splines (using the SciPy library function splrep with smoothing parameter $s=2$ ) over the stimulation periods. The maxima of these smooth spline representations were taken as the response amplitudes. This data processing was performed with customwritten scripts for open-source SciPy (scipy.org), NumPy (numpy.org), and Matplotlib (matplotlib.sf.net) Python libraries. The relative increases in fluorescense $(\Delta F / F)$ were calculated by averaging all dendrite-associated pixels within each frame and dividing the fractional change of fluorescence over time by the prestimulus baseline value of the same pixels.
A
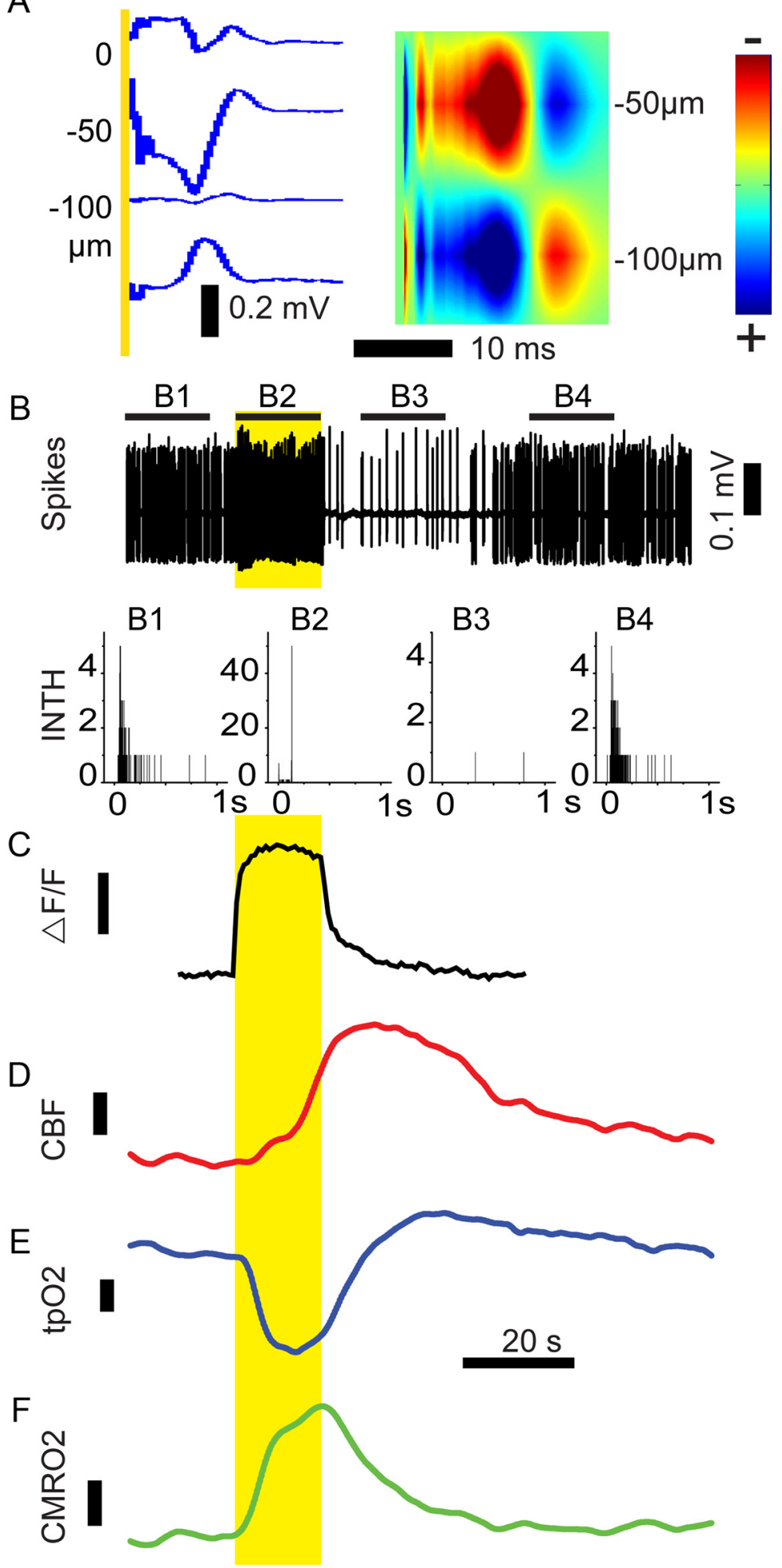

Figure 2. CF-evoked calcium, electrophysiological, and metabolic responses in the mouse cerebellum in vivo. $A$, Depth profile of CF-evoked LFPs recorded at $50 \mu \mathrm{m}$ intervals (left) and calculated CSD map (right) with characteristic negative currents (hot colors, - ) and positive currents (cold colors, +). At A depth of $50 \mu \mathrm{m}$, the negative current represents the fEPSC and the delayed positive current represents the postsynaptic $g \mathrm{~K}_{\mathrm{C} \cdot} \cdot \boldsymbol{B}, \mathrm{PC}$ spike activity before stimulation included both spontaneous simple and complex spikes (CS, SS, top) as shown in the spike INTH (B1, bottom). CS rate increased and SS rate decreased in response to CF stimulation (B2, bottom) followed by a poststimulus $S 5$ refractory period ( $B 3$, top and bottom). The $P($ spike activity returned to baseline levels $\sim 30 \mathrm{~s}$ after the end of stimulation (B4, top and bottom). $\mathbf{C}-\boldsymbol{F}$, ( CF stimulation (yellow-shaded region, $10 \mathrm{~Hz}, 15 \mathrm{~s}$ ) also evoked $\mathrm{Ca}^{2+}$ rises in identified $\mathrm{PC}$ dendrites $(\triangle F / F)(C)$ that returned to normal almost immediately after the end of stimulation, as well as longer lasting changes in $\mathrm{CBF}(\boldsymbol{D}), \mathrm{tpO}_{2}(\boldsymbol{E})$, and $\mathrm{CMRO}_{2}(\boldsymbol{F})$. Calibration, $\boldsymbol{C}, \boldsymbol{D}, \boldsymbol{F}, 10 \%$ changes; $\boldsymbol{E}, 5 \mathrm{mmHg}$. 
A
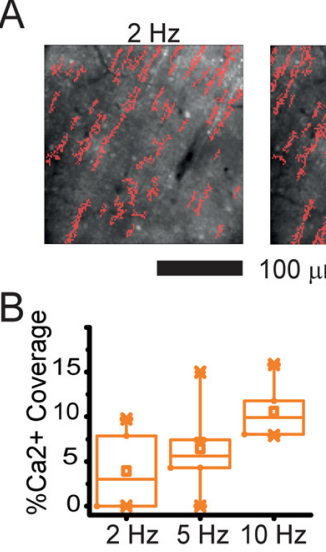

$J$

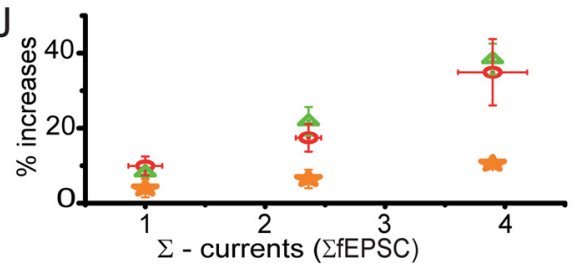

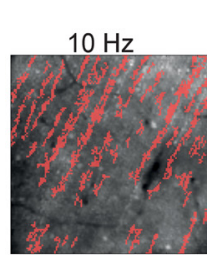

C $2 \mathrm{~Hz}$

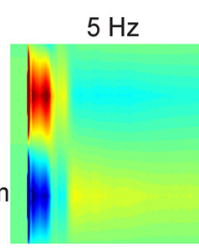

$-$

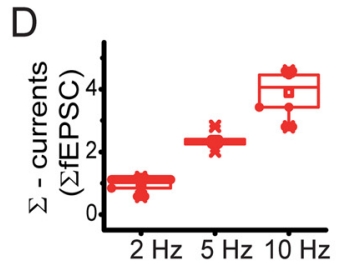

E

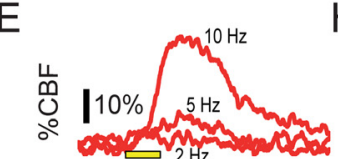

$\mathrm{H}$
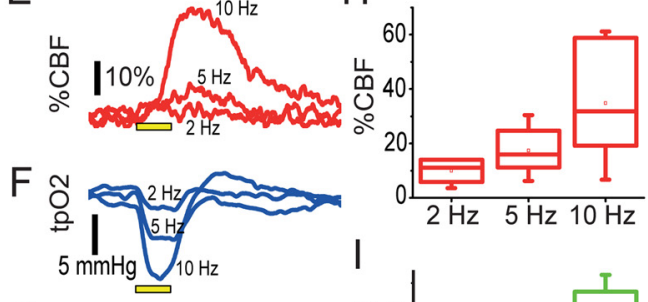

G

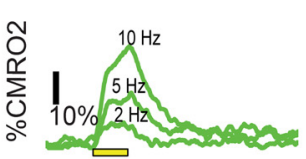

Figure 3. CF stimulation induces frequency-dependent responses in $\mathrm{Ca}^{2+}$ coverage, $\mathrm{fEPSCS}, \mathrm{CBF}, \mathrm{tpO} \mathrm{O}_{2}$, and $\mathrm{CMRO}_{2} \cdot A, \mathrm{Ca}^{2+}$ coverage (see Materials and Methods) during $\mathrm{CF}$ stimulation at 2,5, and $10 \mathrm{~Hz}$. Responding dendrites are indicated by red pixels superimposed on an averaged projection image obtained from the raw data. The number of pixels with a statistically significant $\mathrm{Ca}^{2+}$ signal (the coverage) increased with increasing stimulation frequency. $\boldsymbol{B}$, Boxplot of $\mathrm{Ca}^{2+}$ coverage as a function of stimulation frequency $(N=6)$. $C$, CSD map of evoked postsynaptic activity in PC in response to stimulation with negative currents (hot colors, - ) and positive currents (cold colors, + ). At a depth of $50 \mu \mathrm{m}$, the negative current represents the fEPSC and the delayed positive current represents the postsynaptic $g \mathrm{~K}_{\mathrm{Ca}}{ }^{2+}$. D, Boxplot of the sum of negative currents $\left(\sum \mathrm{fEPSC}=\mathrm{fESPC}\right.$ amplitude $\times$ stimulation frequency $\times$ duration of stimulation train) for each stimulation period $(N=6) . E-G, C F$ stimulation also evoked frequency-dependent changes in $\mathrm{CBF}(\boldsymbol{E}), \mathrm{tpO}_{2}(\boldsymbol{F})$, and $\mathrm{CMRO}_{2}(\boldsymbol{G})$. The yellow bar indicates stimulus duration of $15 \mathrm{~s}$. $\boldsymbol{H}, \boldsymbol{I}, \mathrm{B}$ oxplots show peak increases of $\mathrm{CBF}(H)$ and $\mathrm{CMRO}_{2}(I)(N=6)$. Peak increases of $\mathrm{CBF}$ (red circle), $\mathrm{CMRO}_{2}$ (green triangle), and $\mathrm{Ca}^{2+}$ coverage (orange star) were plotted as a function of the sum of negative currents ( $\Sigma \mathrm{fEPSC}$ ) in $J$. Whiskers indicate SEM.

\section{Drug application}

All drugs were dissolved in aCSF. Muscimol (5-aminoethyl-3-hydroxyisoxazole; Sigma-Aldrich), a classical potent agonist of $\mathrm{GABA}_{\mathrm{A}}$ receptors, was used to induce tonic inhibition; the inhibition was relieved by application of bicuculline ([R- $\left.\left(\mathrm{R}^{*}, \mathrm{~S}^{*}\right)\right]$-5-(6,8-dihydro-8-oxofuro[3,4-e]-1,3-benzodioxol-6-yl)-5,6,7,8-tetrahydro-6,6-dimethyl-1,3-dioxolo[4,5-g]isoquinolinium $\mathrm{Cl}^{-}$; Sigma-Aldrich), a potent and specific $\mathrm{GABA}_{\mathrm{A}}$ antagonist, or gabazine (6-imino-3-(4-methoxyphenyl)-1(6H)-pyridazinebutanoic acid hydrobromide; SR 95531, Sigma-Aldrich), a competitive GABA $_{\mathrm{A}}$ antagonist. These drugs were applied by placing drops of the dissolved compound $(2 \mathrm{~mm})$ on the agarose covering the vermis region. In separate experiments, we topically applied $40 \mu \mathrm{M} \omega$-agatoxin-IVA ( $\omega$-AGA; A6719, SigmaAldrich), a potent and selective $\mathrm{P} / \mathrm{Q}$-type channel blocker, to block postsynaptic $\mathrm{Ca}^{2+}$ entry in PCs (McDonough et al., 2002) or 0.036-0.36 mM Ru360 $\left[(\mu)\left[\left(\mathrm{HCO}_{2}\right)\left(\mathrm{NH}_{3}\right)_{4} \mathrm{Ru}\right] \mathrm{OCl}_{3} ;\right.$ catalog $\# 557440$, Calbiochem $]$, a selective and potent mitochondrial uniporter blocker, to block $\mathrm{Ca}^{2+}$ influx into mitochondria (Ying et al., 1991).

\section{Statistical analysis}

The baseline and slope of the evoked $\mathrm{tpO}_{2}$ were estimated using linear correlation, and $\mathrm{tpO}_{2}$ amplitude was calculated as the difference between the stimulus-evoked negative $\mathrm{tpO}_{2}$ response and the immediately preceding baseline (OriginPro 8.1). $\mathrm{CBF}$ and $\mathrm{CMRO}_{2}$ responses were normalized to the immediately preceding $20 \mathrm{~s}$ baseline, and the maximal response amplitude was estimated using nonlinear curve fitting (Extreme; OriginPro 8.1). Original, non-normalized data were analyzed statistically using correlation analyses to compare $\mathrm{Ca}^{2+}$ transients obtained using two-photon imaging with electrophysiological signals obtained in other experiments using the same experimental protocol. Drug effects of muscimol and $\omega$-AGA were analyzed using a paired $t$ test. As different concentrations of Ru360 were given to separate groups of mice, Ru360 data were analyzed using a mixed-effects model (R, R Development Core Team, R Foundation for Statistical Computing) followed by a paired $t$ test to test for significance at specific time points. Significance level was set at $\alpha=0.05$ (two tailed). Data are presented as mean values \pm SEM in the scatterplots and tables.

\section{Results}

Frequency dependence of neuronal $\mathrm{Ca}^{2+}$, postsynaptic currents, $\mathrm{CBF}$, and $\mathrm{CMRO}_{2}$ during evoked climbing fiber activity

We measured a number of parameters to describe the relationship among transmembrane synaptic currents, cytosolic $\mathrm{Ca}^{2+}$, and $\mathrm{CMRO}_{2}$. Evoked calcium responses in the molecular layer of the cerebellar cortex were imaged using two-photon microscopy. In parallel, we recorded $\mathrm{CBF}, \mathrm{tpO}_{2}, \mathrm{CSD}, \mathrm{LDF}$, and single-unit activity from PC (Fig. 1A-C) (Offenhauser et al., 2005). All data are summarized in Table 1.

Figure $1 C$ illustrates the sagittal orientation of PC dendrites in a Pcp2-eGFP transgenic mouse line. Stimulation of the CFs resulted in fluorescence increases in parasagittal bands indicating activated PC dendrites (Fig. 1D). The bands were usually several dendrites thick, in line with previous studies using $\mathrm{pH}$-sensitive dyes (Chen et al., 1996; Hanson et al., 2000). The cytosolic $\mathrm{Ca}^{2+}$ increases in PC dendrites decayed rapidly after stimulation (Fig. $2 C$ ). In contrast, the $\mathrm{CBF}, \mathrm{tpO}_{2}$, and calculated $\mathrm{CMRO}_{2}$ time courses were more prolonged (Fig. 2D-F).

CF stimulation also gave rise to PC EPSPs (Fig. $2 A$, left), which were transformed into a CSD ratio map (Fig. $2 A$, right). The CSD maps showed a negative current corresponding to the averaged fEPSC with a maximum 5-8 $\mathrm{ms}$ after stimulation, reflecting $\mathrm{Na}^{+}$entry via PC AMPA receptors. A delayed maximum positive current was recorded at the same depth 10-20 ms after stimulation, reflecting an outward $g \mathrm{~K}_{\mathrm{Ca}}{ }^{2+}$ gated by voltagesensitive P/Q-type $\mathrm{Ca}^{2+}$ channels (Llinas, 1981; Womack et al., 
Table 2. Changes from control levels of $\mathrm{Ca}^{2+}$ rises, spike activity, current source density, $\mathrm{CBF}$, and $\mathrm{CMRO}_{2}$

\begin{tabular}{|c|c|c|}
\hline & $N$ & Changes from control level (\%) \\
\hline \multicolumn{3}{|l|}{$\mathrm{Ca}^{2+}$} \\
\hline \multicolumn{3}{|l|}{ Peak } \\
\hline Muscimol $3^{\prime}-60^{\prime}$ & 8 & $-100 \pm 0^{* * *}$ \\
\hline Bicuculline/gabazine & 8 & $-4.4 \pm 7.2 \S \S \S$ \\
\hline$\omega$-AGA 30'-50' & 4 & $-19.9 \pm 34.8$ \\
\hline$\omega-A G A 60^{\prime}-90^{\prime}$ & 4 & $-62.2 \pm 13.1^{*}$ \\
\hline \multicolumn{3}{|l|}{ Coverage } \\
\hline Muscimol $3^{\prime}-60^{\prime}$ & 8 & $-100 \pm 0^{* * *}$ \\
\hline Bicuculline/gabazine & 8 & $-1.5 \pm 15.0 \S \S \S$ \\
\hline$\omega-A G A 30^{\prime}-50^{\prime}$ & 4 & $-66.8 \pm 23.8^{*}$ \\
\hline$\omega-A G A 60^{\prime}-90^{\prime}$ & 4 & $-73.2 \pm 11.5^{* *}$ \\
\hline \multicolumn{3}{|l|}{ Spikes } \\
\hline \multicolumn{3}{|l|}{ Spontaneous } \\
\hline Muscimol & 8 & $-88.6 \pm 10.2^{*}$ \\
\hline Bicuculline/gabazine & 7 & $2.5 \pm 7.6 \%$ \\
\hline$\omega-\operatorname{AGA} 30^{\prime}-50^{\prime}$ & 7 & $-11.8 \pm 7.7$ \\
\hline$\omega-A G A 60^{\prime}-90^{\prime}$ & 7 & $-49.9 \pm 11.4^{*}$ \\
\hline \multicolumn{3}{|l|}{ Evoked } \\
\hline Muscimol & 8 & $-20.1 \pm 10.8$ \\
\hline Bicuculline/gabazine & 7 & $16.7 \pm 57.3$ \\
\hline$\omega$-AGA $30^{\prime}-50^{\prime}$ & 7 & $-10.0 \pm 6.8$ \\
\hline$\omega-A G A 60^{\prime}-90^{\prime}$ & 7 & $-6.7 \pm 17.4$ \\
\hline \multicolumn{3}{|l|}{ Postrefractory } \\
\hline Muscimol & 8 & ND \\
\hline Bicuculline/gabazine & 7 & ND \\
\hline$\omega$-AGA $30^{\prime}-50^{\prime}$ & 7 & $-89.0 \pm 11.0^{*}$ \\
\hline$\omega$-AGA $60^{\prime}-90^{\prime}$ & 7 & $-89.9 \pm 8.2^{*}$ \\
\hline \multicolumn{3}{|l|}{ CSD } \\
\hline \multicolumn{3}{|l|}{ Negative current } \\
\hline Muscimol 10' $-20^{\prime}$ & 6 & $8.3 \pm 10.8$ \\
\hline Muscimol $40^{\prime}-60^{\prime}$ & 9 & $28.2 \pm 11.5^{*}$ \\
\hline Bicuculline/gabazine & 8 & $1.5 \pm 18.2$ \\
\hline$\omega-\operatorname{AGA} 30^{\prime}-50^{\prime}$ & 2 & $-19.9 \pm 8.7$ \\
\hline$\omega-A G A 60^{\prime}-90^{\prime}$ & 2 & $-26.2 \pm 11.0$ \\
\hline \multicolumn{3}{|l|}{ Positive current } \\
\hline Muscimol $10^{\prime}-20^{\prime}$ & 6 & $-54.0 \pm 14.3^{*}$ \\
\hline Muscimol $40^{\prime}-60^{\prime}$ & 9 & $-77.4 \pm 8.8^{*}$ \\
\hline Bicuculline/gabazine & 8 & $-25.1 \pm 16.2 \S$ \\
\hline$\omega$-AGA $30^{\prime}-50^{\prime}$ & 2 & $-29.1 \pm 9.1$ \\
\hline$\omega-A G A 60^{\prime}-90^{\prime}$ & 2 & $-46.3 \pm 2.9$ \\
\hline \multicolumn{3}{|l|}{$\mathrm{CBF}$} \\
\hline \multicolumn{3}{|l|}{ Amplitude } \\
\hline Muscimol 10' $-20^{\prime}$ & 6 & $-9.2 \pm 14.5$ \\
\hline Muscimol $40^{\prime}-60^{\prime}$ & 8 & $-37.1 \pm 6.1^{*}$ \\
\hline Bicuculline/gabazine & 8 & $12.8 \pm 9.5$ \\
\hline$\omega$-AGA $30^{\prime}-50^{\prime}$ & 7 & $-39.7 \pm 17.9^{*}$ \\
\hline$\omega-A G A 60^{\prime}-90^{\prime}$ & 7 & $-37.2 \pm 10.6^{*}$ \\
\hline Ru360 30' & 3 & $42.0 \pm 31.8^{*}$ \\
\hline Ru360 60' & 3 & $21.0 \pm 30.7$ \\
\hline \multicolumn{3}{|l|}{$\mathrm{CMRO}_{2}$} \\
\hline \multicolumn{3}{|l|}{ Amplitude } \\
\hline Muscimol $10^{\prime}-20^{\prime}$ & 6 & $33.2 \pm 29.1$ \\
\hline Muscimol $40^{\prime}-60^{\prime}$ & 8 & $-47.6 \pm 6.8^{*}$ \\
\hline Bicuculline/gabazine & 8 & $17.3 \pm 14.9$ \\
\hline$\omega-A G A 30^{\prime}-50^{\prime}$ & 7 & $25.1 \pm 20.1$ \\
\hline$\omega-A G A 60^{\prime}-90^{\prime}$ & 7 & $-38.3 \pm 14.0^{*}$ \\
\hline Ru360 30' & 3 & $10.5 \pm 6.1$ \\
\hline Ru360 60' & 3 & $-14.9 \pm 6.1$ \\
\hline \multicolumn{3}{|l|}{$\Delta \mathrm{CMRO}_{2} / \mathrm{LFP}$} \\
\hline Ru360 30' & 3 & $0.7 \pm 4.0$ \\
\hline Ru360 60' & 3 & $-2.8 \pm 3.4$ \\
\hline
\end{tabular}

Negative values indicate inhibition, while positive values indicate increases. Using thepaired ttest, statistically significant differences from control levels at $p<0.05,0.01$, or 0.001 are indicated by ${ }^{*},{ }^{* *}$, and ${ }^{* * *}$, respectively; significant differences between the muscimol group and the bicuculline/gabazine group areindicated by $\S, \S \S$, and $\S \S \S$, respectively. Ru360 data represent the average of three concentrations. Changes in current source densityareevaluated using negative currents representing thefEPSC; and positive currents representing the $\mathrm{Ca}^{2+}$-gated $\mathrm{K}^{+}$-current.
2009). The CSD maps also revealed a second positive current at a depth of $100 \mu \mathrm{m}$ with the same timing as the fEPSC (i.e., $5-8 \mathrm{~ms}$ after stimulation), which most likely corresponded to another outward $\mathrm{K}^{+}$current (Frey et al., 2009). PC single-unit recordings showed random firing of both SSs and CSs, as shown in the spike INTH (Fig. 2B1). CF stimulation increased CS and reduced SS firing (Fig. $2 \mathrm{B2}$ ); this was followed by a poststimulus refractory period of SS firing (Fig. $2 B$ ) with longer spike intervals (Fig. 2B3). In normal physiological conditions, the refractory period lasted $\sim 30$ s, after which PC spike activity returned to baseline levels (Fig. 2B4, top).

CFs were stimulated at frequencies of 2,5 , and $10 \mathrm{~Hz}$, evoking increases in synaptic activity, postsynaptic complex spiking, dendritic $\mathrm{Ca}^{2+}, \mathrm{CBF}$, and $\mathrm{CMRO}_{2}$ (Fig. 3). Under control conditions, the evoked $\mathrm{Ca}^{2+}, \sum$ fEPSC, $\mathrm{CBF}$, and $\mathrm{CMRO}_{2}$ responses increased in a frequency-dependent manner. An increased number of pixels with a significant $\mathrm{Ca}^{2+}$ signal was observed as a function of the stimulus frequency (Fig. $3 A, B$ ), indicating that higher rates of CF stimulation recruited more cells. In parallel sets of experiments, we demonstrated that postsynaptic activity as measured by the $\sum$ fEPSC responses correlated linearly with the stimulation frequency (Fig. $3 C, D$ ), and that in the same mice, the increases in $\Sigma$ fEPSC were accompanied by proportional increments in $\mathrm{CBF}$ and $\mathrm{CMRO}_{2}$ (Fig. $3 \mathrm{~F}, I$ ). Combined results from two-photon microscopy and electrophysiological experiments are shown in Figure 3F. A linear correlation was found between normalized $\sum$ fEPSC responses and $\mathrm{CMRO}_{2}\left(r^{2}=0.999\right.$, $p=0.015$ ) (Fig. 3J). The observations that $\mathrm{Ca}^{2+}$ and $\mathrm{CMRO}_{2}$ correlated linearly to the stimulus frequency and that the correlation analysis revealed a clear linear relationship between these two parameters and $\sum$ fEPSC (Fig. $3 J$ ) validates comparison of the imaging and electrophysiological data across different experiments.

\section{The effect of $\mathrm{GABA}_{\mathrm{A}}$ receptor blockade on stimulus-evoked $\mathrm{Ca}^{2+}, \mathrm{CBF}$, and $\mathrm{CMRO}_{2}$}

To explore the coupling among cytosolic $\mathrm{Ca}^{2+}, \mathrm{CBF}$, and $\mathrm{CMRO}_{2}$ transients, we modulated the level of tonic synaptic inhibition with muscimol (Krogsgaard-Larsen and Johnston, 1978), a potent $\mathrm{GABA}_{\mathrm{A}}$ agonist, that suppresses $\mathrm{PC}$ simple spike output and, notably, suppresses PC dendrite $\mathrm{Ca}^{2+}$ responses during CF stimulation (Schreurs et al., 1992; Callaway et al., 1995). We evaluated pharmacological effects on $\mathrm{Ca}^{2+}$ responses by quantifying the total area covered by activated cells in the field of view (Table 2). Muscimol abolished the evoked cytosolic $\mathrm{Ca}^{2+}$ responses in PC dendrites within 3 min of application (Fig. $4 A, F$ ), and $\mathrm{Ca}^{2+}$ responses remained undetectable throughout the period of muscimol exposure. The effects of muscimol were reversed by application of the $\mathrm{GABA}_{\mathrm{A}}$ receptor antagonists bicuculline or gabazine (Fig. 4 A, right; Table 2). While the magnitude of the fEPSC was not affected during muscimol application (Fig. 4B,C; Table 2), the delayed positive current representing the $\mathrm{P} / \mathrm{QCa}^{2+}$ channel-mediated $g \mathrm{~K}_{\mathrm{Ca}}{ }^{2+}$ (McDonough et al., 2002) was reduced (Fig. 4C, bottom). This synaptically activated $g \mathrm{~K}_{\mathrm{Ca}}{ }^{2+}$ returned to normal after application of either bicuculline or gabazine (Table 2; Fig. 4C). Spontaneous PC SS firing decreased within 3-10 min of muscimol application (Fig. 5A, top), while spontaneous CS firing was still present (Fig. $5 A$, middle). Evoked PC CS firing also remained constant throughout muscimol treatment (Fig. 5A, bottom). Since spontaneous CS firing remained unaffected over the course of the experiment, it is unlikely that muscimol diffused to the cerebellar nuclei, which, via inhibitory projections to the inferior olive, could alter CS firing patterns (Stam et al., 2010). In summary, the delayed $g \mathrm{~K}_{\mathrm{Ca}}$ current and spontaneous SS 

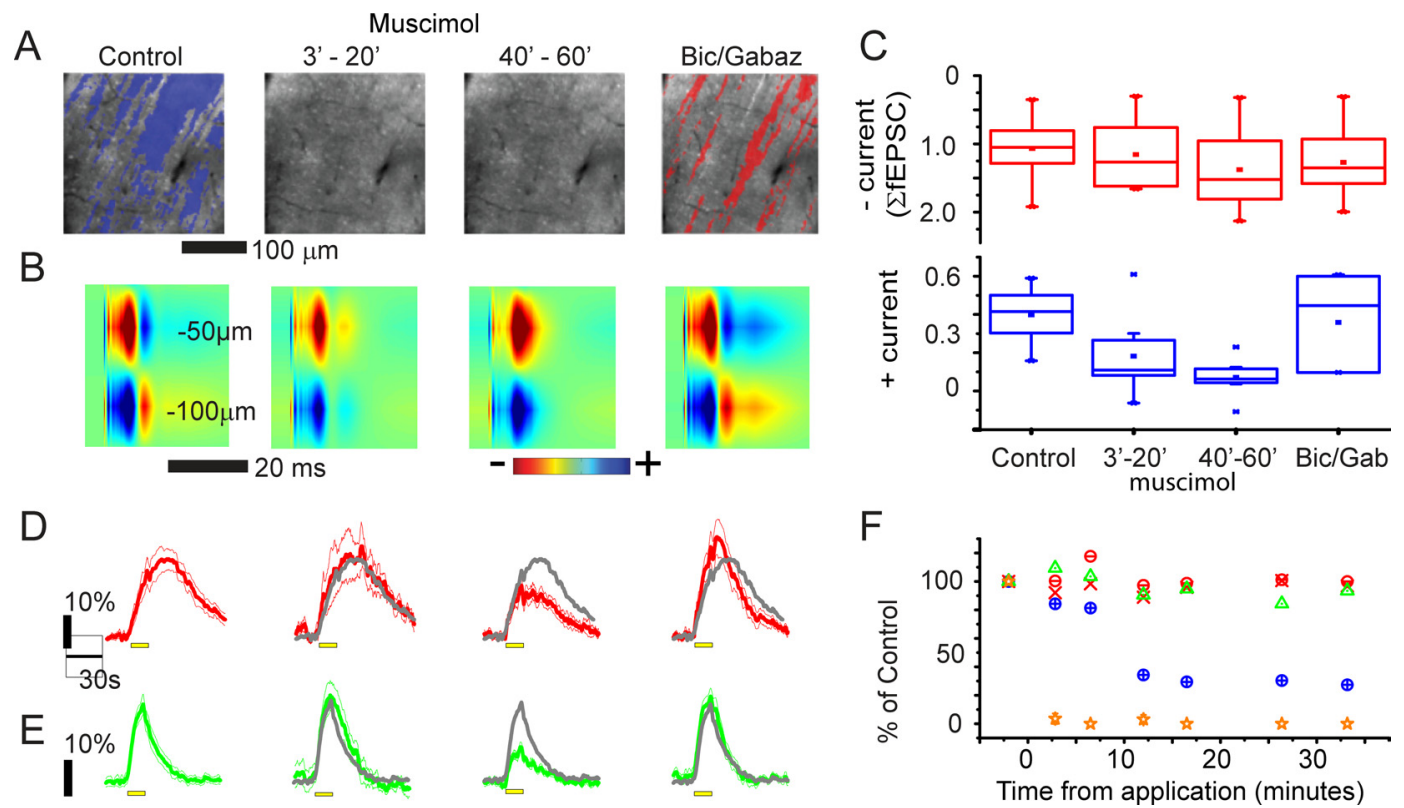

Figure 4. Muscimol decreases dendritic $\mathrm{Ca}^{2+}$ responses in PCs before attenuation of $\mathrm{CBF}$ and $\mathrm{CMRO}_{2}$ responses. CFs were stimulated at $10 \mathrm{~Hz}$ for $15 \mathrm{~s}$, indicated by the yellow bars in $\boldsymbol{D}$ and $E$. $A$, $\mathrm{Ca}^{2+}$ coverage is indicated by blue pixels before, and at 3-20 and 40-60 min after muscimol application. (Note that no dendrite $\mathrm{Ca}^{2+}$ coverage is seen at these last two time points.) After reversal with the $\mathrm{GABA}_{A}$ receptor antagonists bicuculline or gabazine, $\mathrm{Ca}^{2+}$ coverage is indicated by red pixels. The inhibition of $\mathrm{Ca}^{2+}$ responses by muscimol was reversed by $\mathrm{GABA}_{A}$ receptor antagonists, indicating the specificity of the muscimol effect on $\mathrm{GABA}_{\mathrm{A}}$ receptors. In comparison, muscimol had no effect on the fEPSCs (hot colors, - , at depth of $50 \mu \mathrm{m}$ ) in $\boldsymbol{B}$, but did decrease the positive currents (cold colors, + , at depth of $50 \mu \mathrm{m}$ ) due to silencing of the $g \mathrm{~K}_{\mathrm{C} \cdot}$. Data are summarized for all animals in the boxplots of negative current (fEPSC, top) and positive current (bottom) in $C$; the latter was significantly reduced by muscimol at both time periods. Bic, Bicuculline; Gab, gabazine. $\boldsymbol{D}, \boldsymbol{E}$, The corresponding rises in $\mathrm{CBF}(\boldsymbol{D})$ and $\mathrm{CMRO}_{2}(\boldsymbol{E})$ remained unchanged at $3-20$ min $($ second panel) compared with control conditions (first panel), while at $40-60 \mathrm{~min}$ (third panel) both variables decreased. The mean (BF and $\mathrm{CMRO}_{2}$ are represented as solid lines, while dotted lines represent \pm SEM values, and control CBF and $\mathrm{CMRO}_{2}$ responses are shown as superimposed gray traces. Complete reversal was observed after topical application of bicuculline or gabazine (Gabaz)

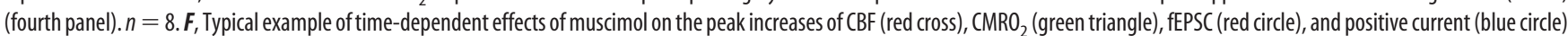
and $\mathrm{Ca}^{2+}$ coverage (orange star), relative to control levels during the first 20 min of muscimol application illustrates the rapid decrease in dendritic $\mathrm{Ca}^{2+}$ responses and $g \mathrm{~K}_{\mathrm{Ca}}$ compared with the other variables. Statistical information appears in Table 2.

activity decreased significantly after muscimol application, while fEPSC and CS firing were unaffected.

Although activity-evoked rises of $\mathrm{CBF}$ and $\mathrm{CMRO}_{2}$ were unaffected up to $20 \mathrm{~min}$ during muscimol exposure (Figs. $4 D, E$; Table $2 ; n=6$ ), they did decrease at a later time point (Fig. $4 D, E$; Table $2 ; n=8$ ). Baseline $\mathrm{CMRO}_{2}$ and CBF levels were unaffected by $\mathrm{GABA}_{\mathrm{A}}$ receptor antagonists. Importantly, evoked $\mathrm{Ca}^{2+}$ signals declined much faster than either $\mathrm{CBF}$ or $\mathrm{CMRO}_{2}$ responses beginning at $\sim 3$ min postapplication. $\mathrm{Ca}^{2+}$ responses were reduced in conjunction with $\mathrm{gK}_{\mathrm{Ca}}$ (delayed positive current). A difference of the decline in the $\mathrm{Ca}^{2+}$ responses relative to the $\mathrm{Ca}^{2+}$-gated $\mathrm{K}^{+}$current could be explained by the larger sampling volume of the CSD recording (Fig. $4 F$ ). The significant difference in timing between the effects of muscimol on $\mathrm{Ca}^{2+}$ transients and $\mathrm{CMRO}_{2}$ responses suggests only a weak correlation between cytosolic $\mathrm{Ca}^{2+}$ and $\mathrm{CMRO}_{2}$.

\section{The effect of $\mathrm{P} / \mathrm{Q}$-type voltage-gated $\mathrm{Ca}^{2+}$ channel block on stimulus-evoked $\mathrm{Ca}^{2+}, \mathrm{CBF}$, and $\mathrm{CMRO}_{2}$}

To further explore the importance of $\mathrm{Ca}^{2+}$, from a predominantly neuronal origin, in mediating stimulus-evoked rises in $\mathrm{CBF}$ and $\mathrm{CMRO}_{2}$, we blocked P/Q-type $\mathrm{Ca}^{2+}$ channels with $\omega$-AGA (McDonough et al., 2002). $\omega$-AGA induced a gradual decline in the number of $\mathrm{PC}$ dendrites exhibiting a $\mathrm{Ca}^{2+}$ response (44\% of control at 30-50 $\mathrm{min}$ ), with nearly complete absence of $\mathrm{Ca}^{2+}$ signals after 60-90 min (Fig. 6A,E; Table 2). The fEPSCs (excitatory negative currents) were unaffected after 30-50 min, but reduced after 60-90 min (Fig. 6B, E; Table 2). Thus, $\omega$-AGA had an immediate $(30 \mathrm{~min})$ effect on $\mathrm{PC}$ cytosolic $\mathrm{Ca}^{2+}$ responses (McDonough et al., 2002) and a delayed (60 min) effect on neurotransmitter release from CF terminals (Doroshenko et al., 1997). $\omega$-AGA also decreased the evoked CBF responses after $30-50 \mathrm{~min}$ with no further reduction at 60-90 $\mathrm{min}$. This finding suggests that part of the blood flow response could be dependent upon the measured $\mathrm{Ca}^{2+}$ response (Fig. 6C,E; Table 2).

Importantly, $\mathrm{CMRO}_{2}$ responses were unchanged at 30-50 min, but were reduced after 60-90 min of $\omega$-AGA exposure (Figs. $6 D, E$; Table 2). Thus, the time course of the decrease in $\mathrm{CMRO}_{2}$ responses followed the decrease in fEPSCs, but not that of the PC cytosolic $\mathrm{Ca}^{2+}$ responses (Fig. 6E; Table 2), which is consistent with the notion that neurometabolic coupling in cerebral and cerebellar cortex primarily reflects synaptic rather than spiking activity (Viswanathan and Freeman, 2007; Lecoq et al., 2009; Thomsen et al., 2009). $\mathrm{CMRO}_{2}$ responses also decreased together with decreases in spontaneous and evoked PC spiking (Fig. 5B). The poststimulus refractory period in SS firing was shortened after $30 \mathrm{~min}$ of $\omega$-AGA application, most likely because of reduced $\mathrm{Ca}^{2+}$ entry in the PC dendrites (Table 2). Figure $6 E$ shows the reductions in $\mathrm{CMRO}_{2}, \mathrm{fEPSC}$, and $\mathrm{Ca}^{2+}$ coverage induced by $\omega$-AGA with time; a linear correlation between $\mathrm{CMRO}_{2}$ and fEPSC amplitude was observed $\left(r^{2}=0.976, p<0.0001\right)$ (Fig. $\left.6 F\right)$, but none was detected between $\mathrm{CMRO}_{2}$ and $\mathrm{Ca}^{2+}$ coverage. Our finding that there was a dissociation between $\mathrm{CMRO}_{2}$ and cytosolic $\mathrm{Ca}^{2+}$ responses questions the hypothesis that evoked rises in $\mathrm{CMRO}_{2}$ require neuronal $\mathrm{Ca}^{2+}$ signaling.

The effect of blocking the mitochondrial uniporter on stimulusevoked $\mathrm{CBF}$ and $\mathrm{CMRO}_{2}$

Mitochondria lie in close juxtaposition to $\mathrm{Ca}^{2+}$ channels of cellular organelles, including those of the plasma membrane (Rizzuto and 
Pozzan, 2006). Microdomains with high $\mathrm{Ca}^{2+}$ concentrations form at the mouths of these channels; besides contributing to global $\mathrm{Ca}^{2+}$ responses, these microdomains may directly supply mitochondria with $\mathrm{Ca}^{2+}$ (Pivovarova et al., 1999). Since our results showed that evoked $\mathrm{CMRO}_{2}$ does not rely on cytosolic $\mathrm{Ca}^{2+}$, we hypothesized that increases in mitochondrial $\mathrm{Ca}^{2+}$ occurring concurrently but independently of global cytosolic $\mathrm{Ca}^{2+}$ responses could. Therefore, to test the importance of mitochondrial $\mathrm{Ca}^{2+}$ for activation-induced oxygen consumption, the mitochondrial uniporter was blocked. Ru360, a cell-permeable oxygen-bridged dinuclear ruthenium red amine complex, specifically blocks $\mathrm{Ca}^{2+}$ uptake into mitochondria in intact cells (Matlib et al., 1998). We found that topical application of this drug caused baseline $\mathrm{CMRO}_{2}$ and $\mathrm{CBF}$ to decrease throughout the first $60 \mathrm{~min}$ of exposure to Ru360 with no further reduction after this $(-7.2 \pm 4.1 \%$ and $-16.0 \pm 3.8 \%$, respectively; $p<0.01$ in both cases). In contrast, a biphasic effect of Ru360 was observed with an initial increase (up to $30 \mathrm{~min}$ ) followed by a decrease on stimulus-evoked $\mathrm{CMRO}_{2}$ and $\mathrm{CBF}$ as well as on evoked field LFPs $(p<0.05)$. Thus, the ratio of $\mathrm{CMRO}_{2}$ to corresponding LFPs remained constant, implying that work-dependent respiration is unaffected when blocking mitochondrial uniporters (Table 2). The constant $\mathrm{CMRO}_{2} /$ LFP ratio in the face of decreasing LFP suggests that Ru360 exerted its effects on synaptic mechanisms. Similarly, the ratio between $\mathrm{CMRO}_{2}$ transients and fEPSCs was constant in the presence of $\omega$-AGA (Fig. $6 F$ ). We surmise that activation-evoked increases in $\mathrm{CMRO}_{2}$ are more closely linked to active transport associated with synaptic and action currents rather than to neuronal $\mathrm{Ca}^{2+}$ signals.

\section{Discussion}

Our study investigated the relationships among CF-evoked neuronal $\mathrm{Ca}^{2+}$ increases, $\mathrm{CMRO}_{2}$, and $\mathrm{CBF}$ in the intact mouse cerebellum. We demonstrate that (1) evoked $\mathrm{PC} \mathrm{Ca}^{2+}$ signals, $\mathrm{CMRO}_{2}$, and CBF scale linearly with stimulus frequency (Fig. $3 F, I)$; (2) that tonic activation of $\mathrm{GABA}_{\mathrm{A}}$ receptors abolishes evoked $\mathrm{Ca}^{2+}$ signals long before abolishing $\mathrm{CBF}$ and $\mathrm{CMRO}_{2}$ transients (Fig. 4F); and (3) that blockade of P/Q-type $\mathrm{Ca}^{2+}$ channels with $\omega$-AGA reduces cytosolic $\mathrm{Ca}^{2+}$ and $\mathrm{CBF}$ but not $\mathrm{CMRO}_{2}$ responses (Fig. 6E). We conclude that increased cytosolic $\mathrm{Ca}^{2+}$ in neurons is not required to control activity-driven $\mathrm{CMRO}_{2}$, an idea consistent with $\mathrm{CMRO}_{2}$ being mainly regulated by ion pumps (Erecińska and Silver, 1989). This is supported by our finding of a conserved ratio between evoked field potentials and $\mathrm{CMRO}_{2}$ transients in the face of changing mitochondrial oxygen consumption induced by Ru360.

A
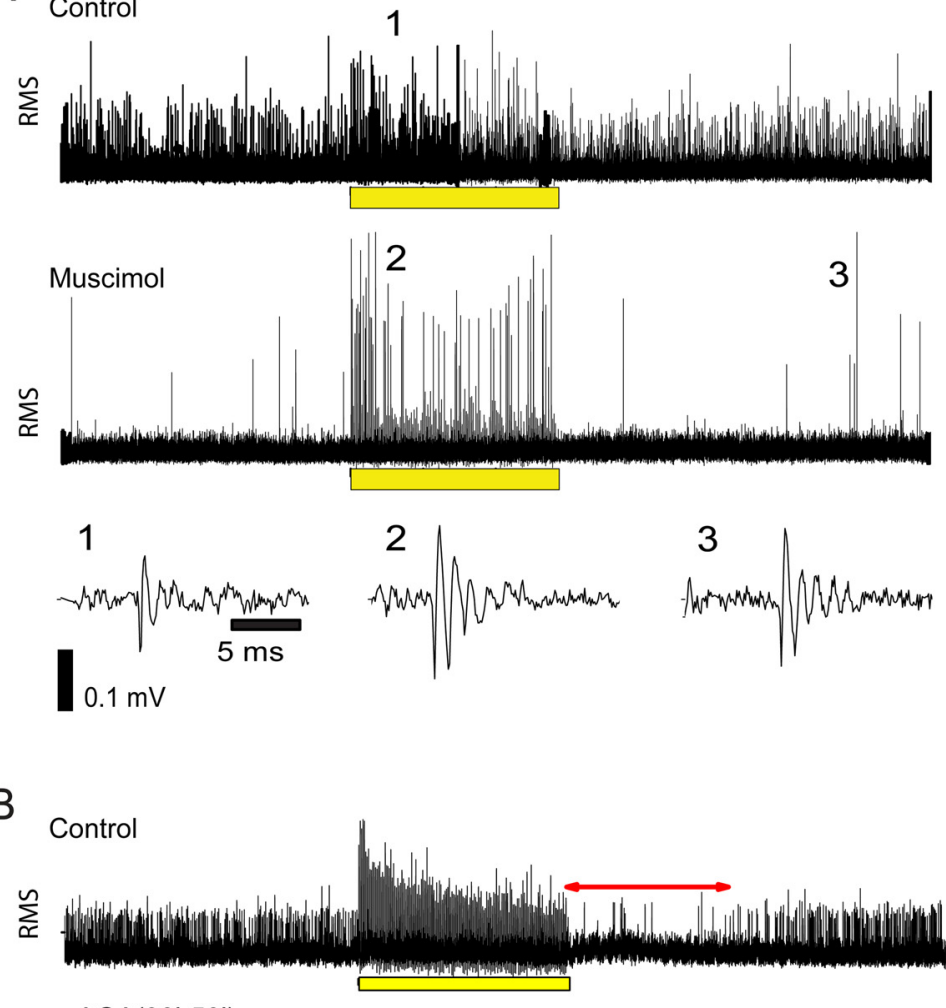

$\omega-A G A\left(30^{\prime}-50^{\prime}\right)$

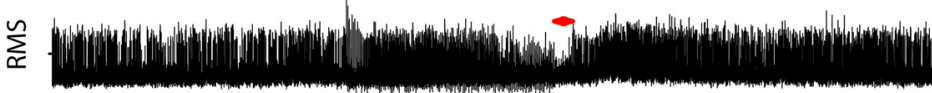

Figure 5. Spontaneous and evoked PC spike activity. $A$, Spontaneous and evoked PC spike activity (evaluated as the rms of the recording taken from 0.3 to $5 \mathrm{kHz}$ ) under control conditions (top trace) and in the presence of muscimol (middle trace). The taneous PC spike rate decreased after application of muscimol; in comparison, the complex spike amplitude increased, and in the presence of $\omega$-AGA (bottom trace). Horizontal red arrows indicate the duration of the poststimulus refractory period, which is the time period from the end of stimulation to the recovery of spike activity back to prestimulus levels. The poststimulus refractory period reflects $g \mathrm{~K}_{\mathrm{Ca}}$ activity mediated by $\mathrm{P} / \mathrm{Q} \mathrm{Ca}^{2+}$ channel activity, which was nearly abolished by $\omega$-AGA. The yellow bars in all panels indicate the duration of $\mathrm{CF}$ stimulation at $10 \mathrm{~Hz}$ and $15 \mathrm{~s}$.

Control of brain energy supply and consumption by activity Increases in neuronal activity primes cellular respiration to supply ATP to the ATPases, which restore ionic gradients across the nerve cell membrane. This accounts for up to $95 \%$ of ATP turnover (Erecińska and Silver, 1989). ATP breakdown transiently increases the level of ADP and the feedback of ADP and inorganic phosphate to the mitochondria. This strategy is the default mechanism by which activity controls cellular respiration and ATP supply (Gunter et al., 2004). In addition, $\mathrm{Ca}^{2+}$ signaling can increase oxidative phosphorylation in two ways (Gunter et al., 2004; Pardo et al., 2006; Satrústegui et al., 2007; Gunter and Sheu, 2009). Mitochondrial $\mathrm{Ca}^{2+}$ influx via the $\mathrm{Ca}^{2+}$ uniporter is followed by activation of dehydrogenases localized to the mitochondrial matrix, resulting in increased TCA cycle activity and ATP production (Satrústegui et al., 2007). Alternatively, small cytosolic $\mathrm{Ca}^{2+}$ signals can induce ATP production through a mechanism independent of mitochondrial $\mathrm{Ca}^{2+}$ elevation. Such a mechanism requires $\mathrm{Ca}^{2+}$-dependent mitochondrial carriers (e.g., the malate-aspartate shuttle), which transfers NADH 

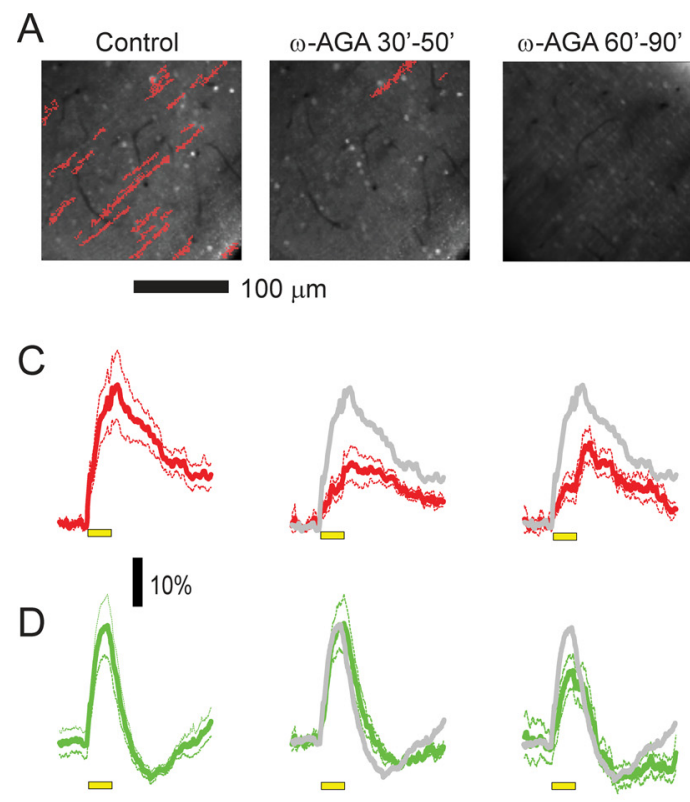
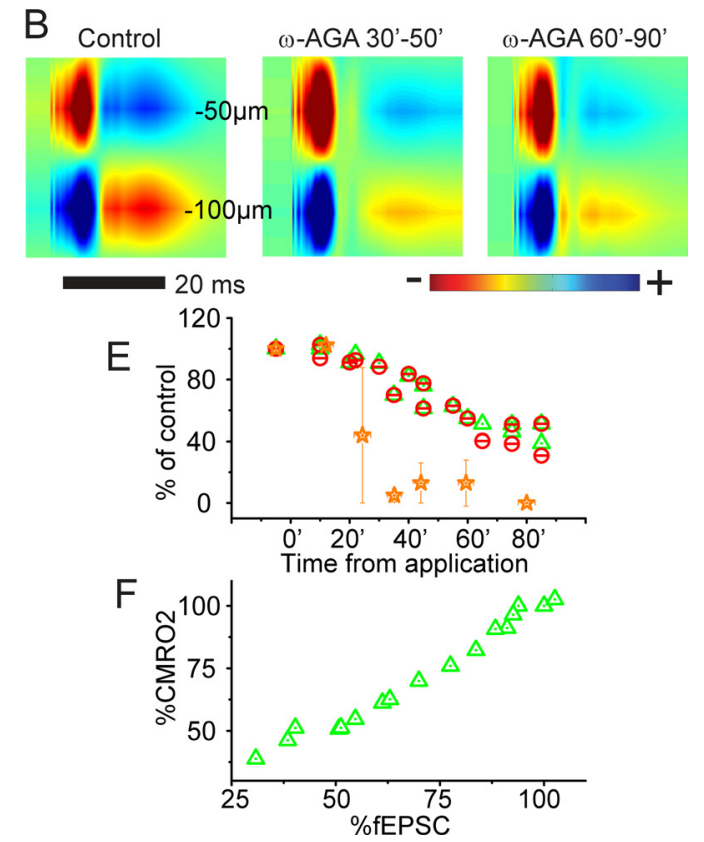

Figure 6. $\omega$-AGA reduces evoked $\mathrm{Ca}^{2+}$ and $\mathrm{CBF}$ responses independently of preserved $\mathrm{fEPSC}$ and $\mathrm{CMRO}_{2}$ responses. CFs were stimulated at $10 \mathrm{~Hz}$ for $15 \mathrm{~s}$, as indicated by the yellow bar in $\mathrm{C}$ and D. $A, \mathrm{Ca}^{2+}$ coverage (red pixels) before and after application of $\omega$-AGA reveals reduced dendritic $\mathrm{Ca}^{2+}$ coverage at $30-50$ and $60-90$ min with $\omega$-AGA. B, CSD analysis with negative currents (hot colors, - ) and positive currents (cold colors, + ). At a depth of $50 \mu \mathrm{m}$, the negative current represents the fEPSC and the delayed positive current represents the postsynaptic $g \mathrm{~K}_{\mathrm{Ca}}$. The fESPCs remained constant during the first $50 \mathrm{~min}$ of $\omega$-AGA exposure, while at $60-90 \mathrm{~min}$ the fEPSCs were reduced. In comparison, $g \mathrm{~K}_{\mathrm{Ca}}$ was reduced from $30 \mathrm{~min}$ onward ( $\boldsymbol{B}$, second and third panels). In $\boldsymbol{C}$ and $\boldsymbol{D}$, traces are represented as mean value \pm SEM (dashed lines). $\boldsymbol{C}$, $\omega$-AGA induced decreased (BF responses at $30-50$ and $60-90$ min after exposure, suggesting a $\mathrm{Ca}^{2+}$-dependent component of $\mathrm{CBF}$ control. Gray traces in middle and right panels indicate the control response. $D$, $\mathrm{CMRO}_{2}$ was unaffected at $30-50 \mathrm{~min}$, but was reduced $60-90$ min after $\omega$-AGA exposure. The reduction in $\mathrm{CMRO}_{2}$ coincided with the reduction in fEPSCs and occurred later than the reduction in dendritic $\mathrm{Ca}^{2+}$ responses. $E$, Time course of reduction in $\mathrm{CMRO}_{2}$ responses (green triangles), $\mathrm{Ca}^{2+}$ coverage (orange stars), and fEPSC (red circles) relative to control levels during the $90 \mathrm{~min}$ following application of $\omega$ - $\mathrm{AGA}(N=2) . \mathrm{Ca}^{2+}$ responses started to decrease before the fEPSC and CMRO responses, which decreased in parallel $(N=4)$. $\boldsymbol{F}$, Linear correlation between fEPSC and $\mathrm{CMRO}_{2}$ responses $\left(r^{2}=0.976, p<0.0001\right.$; see Table 2$)$.

equivalents into the mitochondria (Pardo et al., 2006; Satrústegui et al., 2007). Thus, neurons could match or possibly anticipate the ATP consumption of ion pumps by using cytosolic $\mathrm{Ca}^{2+}$ elevations to increase mitochondrial respiration (Gunter et al., 2004). Recently, a study of isolated brain mitochondria suggested that brain ATP production and thus $\mathrm{CMRO}_{2}$ are controlled by a feedforward mechanism exclusively involving non-mitochondrial $\mathrm{Ca}^{2+}$ (Gellerich et al., 2010). Furthermore, in isolated PCs in vitro, increased cytosolic $\mathrm{Ca}^{2+}$ evoked by high extracellular $\mathrm{K}^{+}$induced both mitochondrial depolarization due to mitochondrial $\mathrm{Ca}^{2+}$ entry via the uniporter and an immediate burst in $\mathrm{O}_{2}$ consumption (Hayakawa et al., 2005). In the cerebellum, the mitochondrial marker cytochrome oxidase is localized to PCs, while Bergmann glia exhibit considerably lower oxidative capacities (Kasischke, 2008). It is therefore a reasonable assumption that the $\mathrm{CMRO}_{2}$ responses we measured primarily reflect respiration in neurons.

\section{Mechanisms of activity-driven $\mathrm{CMRO}_{2}$ responses}

Application of the $\mathrm{GABA}_{\mathrm{A}}$ receptor agonist muscimol abolished or reduced spontaneous PC SS activity almost instantaneously and abolished $\mathrm{PC}$ dendritic $\mathrm{Ca}^{2+}$ responses within a few minutes (Figs. 4A, 5A). At the same time, baseline levels of CBF and $\mathrm{CMRO}_{2}$ were unchanged (Fig. 4D,E) (Caesar et al., 2008b; Thomsen et al., 2009). CF-evoked fEPSC and complex spiking responses remained constant (Figs. $4 B, C, 5 A$ ), indicating that the ion fluxes, and hence the workload, on the $\mathrm{Na}^{+} / \mathrm{K}^{+}$ATPase was unchanged. Only after $40 \mathrm{~min}$ of drug exposure did CBF and $\mathrm{CMRO}_{2}$ responses begin to decline (Fig. 4D,E). Gabazine, a specific antagonist of $\mathrm{GABA}_{\mathrm{A}}$ receptors, reversed the effects of muscimol on cytosolic $\mathrm{Ca}^{2+}, \mathrm{CBF}$, and $\mathrm{CMRO}_{2}$ responses (Fig.
$4 A, D, E)$, suggesting that the muscimol effect required specific interaction with $\mathrm{GABA}_{\mathrm{A}}$ receptors. Previous studies have indicated that the stimulation-evoked rises in CBF can be reduced by 80-90\% without concomitant reductions in the evoked electrophysiological signal (Offenhauser et al., 2005; Caesar et al., 2008b; Leithner et al., 2010). CF stimulation evokes large rises in lactate that are coupled to rises in synaptic activity and spike rate (Caesar et al., 2008a). Thus, in the cerebellum preservation of normal function and restoration of ionic gradients is powered by both glycolysis and respiration (Reinert et al., 2011). Likewise, stimulation of parallel fiber beams increases respiration and aerobic glycolysis (Thomsen et al., 2009). Therefore, under normal conditions there is a dynamic balance between respiration and glycolysis, and when $\mathrm{CMRO}_{2}$ is reduced, glycolysis is assumed to be increased acutely. Therefore, the linear correlation for EPSC versus $\mathrm{CMRO}_{2}$ applies for unperturbed and "drug-naïve" systems, while becoming uncoupled when the level of tonic synaptic inhibition increases (Caesar et al., 2008b).

Our current data, obtained in mice, displayed a slower time course of the muscimol effect than our previous observations in rats, which exhibited a faster onset of the depression of $\mathrm{CBF}$ and $\mathrm{CMRO}_{2}$ responses following muscimol exposure (Caesar et al., 2008b). Thus, the cytosolic $\mathrm{Ca}^{2+}$ and $\mathrm{CMRO}_{2}$ responses were more obviously dissociated in time in mice. We examined this dissociation using a specific blocker of P/Q-type $\mathrm{Ca}^{2+}$ channels, $\omega$-AGA (McDonough et al., 2002). $\omega$-AGA did not influence basal $\mathrm{CBF}, \mathrm{CMRO}_{2}$, or CS firing, but did lead to a decline in the evoked $\mathrm{Ca}^{2+}$ rises in PC dendrites (Fig. $6 A, E$ ). The onset of this decline was delayed compared with that observed during muscimol application (Fig. $4 F$ ), which may be explained by a slower diffusion rate of $\omega$-AGA. Thus, $30 \mathrm{~min}$ after application, $\mathrm{Ca}^{2+}$ 
and $\mathrm{CBF}$ responses were moderately affected (Fig. $6 C$ ), while $\mathrm{CMRO}_{2}$ responses remained constant (Fig. 6D). The physiological effect of $\omega$-AGA was additionally verified by the observation that the drug reduced the poststimulation pause in spontaneous SS activity (Fig. $5 B$; Table 2). $\omega$-AGA led to a gradual reduction in the fEPSC amplitude that closely matched the concomitant reduction in $\mathrm{CMRO}_{2}$ responses (Fig. $6 E, F$ ) due to blocking presynaptic $\mathrm{Ca}^{2+}$ channels on CF terminals (Doroshenko et al., 1997). These experiments demonstrated that cytosolic $\mathrm{Ca}^{2+}$ transients did not modulate $\mathrm{CMRO}_{2}$ responses to CF stimulation. Notably, the reduction in $\mathrm{CMRO}_{2}$ seen after prolonged $\omega$-AGA exposure was not due to a direct effect of $\mathrm{Ca}^{2+}$ on cellular respiration, but due to a reduced workload (i.e., reduced ion flux over the plasma membrane, as indicated by decreased fEPSC amplitude). The close proximity of mitochondria to $\mathrm{Ca}^{2+}$ channels in the plasma membrane and endoplasmic reticulum (Rizzuto and Pozzan, 2006) raises the possibility of mitochondrial $\mathrm{Ca}^{2+}$ transients regulating cellular respiration independently of transient increases in cytosolic $\mathrm{Ca}^{2+}$. Therefore, we blocked mitochondrial $\mathrm{Ca}^{2+}$ entry with Ru360, which resulted in a gradual time-dependent decrease in basal $\mathrm{CMRO}_{2}$. By contrast, stimulation-evoked $\mathrm{CMRO}_{2}$ responses, showed an initial enhancement followed by a reduction in the presence of Ru360. Importantly, LFP amplitude followed a similar time course as $\mathrm{CMRO}_{2}$, resulting in a conserved ratio between $\mathrm{CMRO}_{2}$ and LFP during the entire exposure to Ru360. This finding suggests that the different $\mathrm{CMRO}_{2}$ responses in the presence of Ru360 are due to variations in workload as was found with $\omega$-AGA. Together with our results demonstrating dissociations between $\mathrm{Ca}^{2+}$ and $\mathrm{CMRO}_{2}$ during muscimol and $\omega$-AGA application, these data support the notion that cytosolic $\mathrm{Ca}^{2+}$ does not modulate activity-evoked rises in $\mathrm{CMRO}_{2}$ in the intact cerebellum. Furthermore, blocking $\mathrm{Ca}^{2+}$ channels in neurons and mitochondria with $\omega$-AGA and Ru360 did not affect the amount of $\mathrm{O}_{2}$ consumed per unit work. Our study does not rule out the possibility of presynaptic $\mathrm{Ca}^{2+}$ transients affecting $\mathrm{CMRO}_{2}$ via decreased neurotransmitter release, as suggested by the reduction in fESPCs and LFPs or the possibility of postsynaptic $\mathrm{Ca}^{2+}$ transients in PC dendrites contributing to downstream mechanisms (e.g., dilation of local blood vessels, as suggested by the coordinated reduction of $\mathrm{CBF}$ and $\mathrm{Ca}^{2+}$ responses seen with $\omega$-AGA). We did find that preserved function of the mitochondrial $\mathrm{Ca}^{2+}$ uniporter was necessary for maintaining basal, ongoing $\mathrm{CMRO}_{2}$ and $\mathrm{CBF}$ levels.

In conclusion, we performed $\mathrm{Ca}^{2+}$ imaging of $\mathrm{PC}$ dendrites in the cerebellar cortex of anesthetized mice to evaluate the contribution of cytosolic $\mathrm{Ca}^{2+}$ transients to the control of activitydependent increases in $\mathrm{CMRO}_{2}$. Our observations suggest that cytosolic $\mathrm{Ca}^{2+}$ increases are not rate limiting for activitydependent increases in $\mathrm{CMRO}_{2}$. Here we report that $\mathrm{CMRO}_{2}$ is strongly related to the level of synaptic and action potential currents. We suggest that activity-driven rises in $\mathrm{CMRO}_{2}$ are triggered by a feedback mechanism involving changes in the ATP/ ADP ratio. One explanation for the observed lack of influence of $\mathrm{Ca}^{2+}$ on in vivo $\mathrm{CMRO}_{2}$ may be that the exchange rate between the mitochondrial and cytosolic metabolite pools is fast relative to the neuronal TCA cycle flux (de Graaf et al., 2004). Therefore, in healthy mouse brain tissue, there may be limited requirement for either increased uptake of NADH by mitochondria or an enhanced production of TCA intermediates via $\mathrm{Ca}^{2+}$-dependent mechanisms (Satrústegui et al., 2007). One limitation of our study is that, while the majority of the $\mathrm{Ca}^{2+}$ signal derives from PCs, we cannot exclude smaller contributions from Bergman glia to the $\mathrm{Ca}^{2+}$ signal and even to the increase in $\mathrm{CMRO}_{2}$. Also, our study is restricted to one particular structure and neuronal circuit, and we cannot generalize across brain regions or species. Further studies are needed to extend the findings from the CF-PC circuit in the mouse cerebellum to other circuits.

\section{References}

Attwell D, Buchan AM, Charpak S, Lauritzen M, Macvicar BA, Newman EA (2010) Glial and neuronal control of brain blood flow. Nature 468:232-243.

Caesar K, Thomsen K, Lauritzen M (2003) Dissociation of spikes, synaptic activity, and activity-dependent increments in rat cerebellar blood flow by tonic synaptic inhibition. Proc Natl Acad Sci U S A 100:16000-16005.

Caesar K, Hashemi P, Douhou A, Bonvento G, Boutelle MG, Walls AB, Lauritzen $M$ (2008a) Glutamate receptor-dependent increments in lactate, glucose and oxygen metabolism evoked in rat cerebellum in vivo. J Physiol 586:1337-1349.

Caesar K, Offenhauser N, Lauritzen M (2008b) Gamma-aminobutyric acid modulates local brain oxygen consumption and blood flow in rat cerebellar cortex. J Cereb Blood Flow Metab 28:906-915.

Callaway JC, Lasser-Ross N, Ross WN (1995) IPSPs strongly inhibit climbing fiber-activated $\left[\mathrm{Ca}^{2+}\right]_{\mathrm{i}}$ increases in the dendrites of cerebellar Purkinje neurons. J Neurosci 15:2777-2787.

Chen G, Hanson CL, Ebner TJ (1996) Functional parasagittal compartments in the rat cerebellar cortex: an in vivo optical imaging study using neutral red. J Neurophysiol 76:4169-4174.

Clarke DD, Sokoloff L (1994) Circulation and energy metabolism of the brain. In: Basic neurochemistry: molecular, cellular, and medical (Siegel GJ, Agranoff BW, Albers RW, Molinoff PB, eds), pp 645-680. New York: Raven.

de Graaf RA, Mason GF, Patel AB, Rothman DL, Behar KL (2004) Regional glucose metabolism and glutamatergic neurotransmission in rat brain in vivo. Proc Natl Acad Sci U S A 101:12700-12705.

Doroshenko PA, Woppmann A, Miljanich G, Augustine GJ (1997) Pharmacologically distinct presynaptic calcium channels in cerebellar excitatory and inhibitory synapses. Neuropharmacology 36:865-872.

Erecińska M, Silver IA (1989) ATP and brain function. J Cereb Blood Flow Metab 9:2-19.

Fabricius M, Lauritzen M (1996) Laser-Doppler evaluation of rat brain microcirculation: comparison with the [14C]-iodoantipyrine method suggests discordance during cerebral blood flow increases. J Cereb Blood Flow Metab 16:156-161.

Fabricius M, Akgören N, Dirnagl U, Lauritzen M (1997) Laminar analysis of cerebral blood flow in cortex of rats by laser-Doppler flowmetry: a pilot study. J Cereb Blood Flow Metab 17:1326-1336.

Frey U, Egert U, Heer F, Hafizovic S, Hierlemann A (2009) Microelectronic system for high-resolution mapping of extracellular electric fields applied to brain slices. Biosens Bioelectron 24:2191-2198.

Gellerich FN, Gizatullina Z, Trumbeckaite S, Nguyen HP, Pallas T, Arandarcikaite O, Vielhaber S, Seppet E, Striggow F (2010) The regulation of OXPHOS by extramitochondrial calcium. Biochim Biophys Acta 1797:1018-1027.

Gjedde A (2005) Blood-brain transfer and metabolism of oxygen. In: Bloodbrain barriers: from ontogeny to artificial interfaces, (Dermietzel R, Spray DC, Nedergaard M, eds), pp 523-550. Hoboken: John Wiley and Sons.

Gunter TE, Sheu SS (2009) Characteristics and possible functions of mitochondrial $\mathrm{Ca}(2+)$ transport mechanisms. Biochim Biophys Acta 1787:1291-1308.

Gunter TE, Yule DI, Gunter KK, Eliseev RA, Salter JD (2004) Calcium and mitochondria. FEBS Lett 567:96-102.

Hanson CL, Chen G, Ebner TJ (2000) Role of climbing fibers in determining the spatial patterns of activation in the cerebellar cortex to peripheral stimulation: an optical imaging study. Neuroscience 96:317-331.

Hayakawa Y, Nemoto T, Iino M, Kasai H (2005) Rapid Ca-2+(-)dependent increase in oxygen consumption by mitochondria in single mammalian central neurons. Cell Calcium 37:359-370.

Kann O, Kovács R (2007) Mitochondria and neuronal activity. Am J Physiol Cell Physiol 292:C641-C657.

Kasischke KA (2008) A new pathway for lactate production in the CNS. J Physiol 586:1207-1208.

Krogsgaard-Larsen P, Johnston GA (1978) Structure-activity studies on the inhibition of GABA binding to rat brain membranes by muscimol and related compounds. J Neurochem 30:1377-1382. 
Lauritzen M (2005) Opinion: reading vascular changes in brain imaging: is dendritic calcium the key? Nat Rev Neurosci 6:77-85.

Lecoq J, Tiret P, Najac M, Shepherd GM, Greer CA, Charpak S (2009) Odorevoked oxygen consumption by action potential and synaptic transmission in the olfactory bulb. J Neurosci 29:1424-1433.

Leithner C, Royl G, Offenhauser N, Füchtemeier M, Kohl-Bareis M, Villringer A, Dirnagl U, Lindauer U (2010) Pharmacological uncoupling of activation induced increases in $\mathrm{CBF}$ and $\mathrm{CMRO} 2$. J Cereb Blood Flow Metab 30:311-322.

Lin AL, Fox PT, Hardies J, Duong TQ, Gao JH (2010) Nonlinear coupling between cerebral blood flow, oxygen consumption, and ATP production in human visual cortex. Proc Natl Acad Sci U S A 107:8446-8451.

Llinas RR (1981) Electrophysiology of cerebellar networks. In: Handbook of physiology, section I, the nervous system, Vol II, motor control, Part 2, American Physiological Society (Brooks VB, ed), pp 831-877. Baltimore, MD: Williams and Wilkins.

Mathiesen C, Caesar K, Akgören N, Lauritzen M (1998) Modification of activity-dependent increases of cerebral blood flow by excitatory synaptic activity and spikes in rat cerebellar cortex. Journal of Physiology 512:555-566.

Matlib MA, Zhou Z, Knight S, Ahmed S, Choi KM, Krause-Bauer J, Phillips R, Altschuld R, Katsube Y, Sperelakis N, Bers DM (1998) Oxygen-bridged dinuclear ruthenium amine complex specifically inhibits $\mathrm{Ca} 2+$ uptake into mitochondria in vitro and in situ in single cardiac myocytes. J Biol Chem 273:10223-10231.

McDonough SI, Boland LM, Mintz IM, Bean BP (2002) Interactions among toxins that inhibit N-type and P-type calcium channels. J Gen Physiol 119:313-328.

Nakagawa H, Matsumoto N (1998) ON and OFF channels of the frog optic tectum revealed by current source density analysis. J Neurophysiol 80:1886-1899.

Nicholson C, Freeman JA (1975) Theory of current source-density analysis and determination of conductivity tensor for anuran cerebellum. J Neurophysiol 38:356-368.

Offenhauser N, Thomsen K, Caesar K, Lauritzen M (2005) Activity-induced tissue oxygenation changes in rat cerebellar cortex: interplay of postsynaptic activation and blood flow. J Physiol 565:279-294.

Pardo B, Contreras L, Serrano A, Ramos M, Kobayashi K, Iijima M, Saheki T,
Satrústegui J (2006) Essential role of aralar in the transduction of small $\mathrm{Ca} 2+$ signals to neuronal mitochondria. J Biol Chem 281:1039-1047.

Pivovarova NB, Hongpaisan J, Andrews SB, Friel DD (1999) Depolarizationinduced mitochondrial Ca accumulation in sympathetic neurons: spatial and temporal characteristics. J Neurosci 19:6372-6384.

Raichle ME, Mintun MA (2006) Brain work and brain imaging. Annu Rev Neurosci 29:449-476.

Reinert KC, Gao W, Chen G, Wang X, Peng YP, Ebner TJ (2011) Cellular and metabolic origins of flavoprotein autofluorescence in the cerebellar cortex in vivo. Cerebellum 10:585-599.

Rizzuto R, Pozzan T (2006) Microdomains of intracellular Ca2+: molecular determinants and functional consequences. Physiol Rev 86:369-408.

Satrústegui J, Pardo B, Del Arco A (2007) Mitochondrial transporters as novel targets for intracellular calcium signaling. Physiol Rev 87:29-67.

Schreurs BG, Sanchez-Andres JV, Alkon DL (1992) GABA-induced responses in Purkinje cell dendrites of the rabbit cerebellar slice. Brain Res 597:99-107.

Stam AH, de Vries B, Janssens AC, Vanmolkot KR, Aulchenko YS, Henneman P, Oostra BA, Frants RR, van den Maagdenberg AM, Ferrari MD, van Duijn CM, Terwindt GM (2010) Shared genetic factors in migraine and depression Evidence from a genetic isolate Evidence from a genetic isolate. Neurology 74:288-294.

Thomsen K, Piilgaard H, Gjedde A, Bonvento G, Lauritzen M (2009) Principal cell spiking, postsynaptic excitation, and oxygen consumption in the rat cerebellar cortex. J Neurophysiol 102:1503-1512.

Viswanathan A, Freeman RD (2007) Neurometabolic coupling in cerebral cortex reflects synaptic more than spiking activity. Nat Neurosci 10:1308-1312.

Womack MD, Hoang C, Khodakhah K (2009) Large conductance calciumactivated potassium channels affect both spontaneous firing and intracellular calcium concentration in cerebellar Purkinje neurons. Neuroscience 162:989-1000.

Ying WL, Emerson J, Clarke MJ, Sanadi DR (1991) Inhibition of mitochondrial calcium ion transport by an oxo-bridged dinuclear ruthenium ammine complex. Biochemistry 30:4949-4952.

Zhu XH, Zhang Y, Tian RX, Lei H, Zhang N, Zhang X, Merkle H, Ugurbil K, Chen W (2002) Development of O-17 NMR approach for fast imaging of cerebral metabolic rate of oxygen in rat brain at high field. Proc Natl Acad Sci U S A 99:13194-13199. 